\title{
El Sistema de Tribunales de Inversión. Posibles incompatibilidades con el Derecho europeo*,**
}

\author{
The Investment Court System. \\ Potential incompatibilities with European Union Law
}

\author{
Ana Mercedes López Rodríguez \\ Profesora titular de Derecho internacional privado \\ Universidad Loyola Andalucía \\ amlopez@uloyola.es
}

doi: http://dx.doi.org/10.18543/ced-57-2017pp29-68

Sumario: I. Introducción.-II. Las particularidades del arbitraje de inversiones como método de resolución de controversias. Críticas a su actual configuración.-III. Hacia un Tribunal de Inversiones en la Unión Europea.-IV. El Sistema de Tribunales de Inversión.-V. Análisis del Sistema de Tribunales de Inversión desde la perspectiva del Derecho europeo.-VI. Conclusiones.

Resumen: Con la entrada en vigor del Tratado de Lisboa en 2009 la Unión Europea ha adquirido la competencia exclusiva en materia de inversiones extranjeras directas (art. 207 TFUE), convirtiéndose junto a la política comercial común en uno de los principales pilares de la acción exterior de la misma. Esta circunstancia ha hecho que la Unión Europea haya interpretado esta nueva competencia como una oportunidad para intentar un tratamiento comprensivo de los temas de comercio e inversión a nivel europeo y para proponer una reforma profunda del sistema tradicional de protección de inversiones y de los mecanismos de resolución de controversias inversor-Estado, conocidos en sus siglas anglosajonas de ISDS. Entre las reformas propuestas destaca la creación de un Tribunal Internacional de Inversiones, propuesta no exenta de polémica y que encontraría posibles escollos desde el punto de vista del Derecho de la Unión.

Palabras clave: Inversiones extranjeras, arbitraje de inversiones, Sistema de Tribunales de Inversión, Asociación Transatlántica de Comercio e Inversión (TTIP), Acuerdo Económico y Comercial Global (CETA).

* Recibido el 10 de noviembre de 2016, aceptado el 11 de mayo de 2017.

** El presente estudio se enmarca dentro de la Red de Excelencia sobre «Los actuales desafíos del Derecho Internacional», del Plan Estatal de Investigación Científica y Técnica y de Innovación 2013-2016 (DER15-69273-RED). 
Abstract: With the entry into force of the Lisbon Treaty in 2009 the European Union has taken an exclusive competence on foreign direct investments (art. 207 TFEU). Together with the common commercial policy, it is now one of the main pillars of the external action of the EU. The Union has seen this new competence as a good opportunity to undertake a comprehensive regulation of trade and investment issues at the European level, including a major reform of the traditional mechanisms of Investor-State Dispute Settlement (ISDS). The proposed reforms include the creation of an International Investment Court, but this proposal is controversial and faces potential legal pitfalls from the point of view of EU law.

Keywords: Foreign investments, ISDS, International Investment Court, TTIP, CETA.

\section{Introducción}

Con la entrada en vigor del Tratado de Lisboa en 2009 la política comercial se ha convertido en uno de los pilares de la acción exterior de la Unión Europea (art. 207 TFUE) y ésta ha adquirido la competencia exclusiva en materia de inversiones extranjeras directas. ${ }^{2}$ Como consecuencia de esta nueva competencia la Unión ha adoptado nuevos reglamentos destinados a articular la transición del antiguo modelo de Acuerdos bilaterales de inversión (BITs) firmados por los Estados Miembros $^{2}$ y a clarificar de la responsabilidad financiera entre los Estados Miembros y la Unión Europea en caso de conflicto. ${ }^{3}$ Asimismo ha puesto en marcha la negociación de una serie de acuerdos de inversión con otros Estados, como Canadá, Estados Unidos, Vietnam o Singapur ya como titular de la capacidad para su firma ${ }^{4}$ y

${ }^{1}$ Francisco José Pascual Vives, «El Subsistema Regional Comunitario ante el Régimen Internacional de Protección de las Inversiones Extranjeras». Revista de Derecho Comunitario Europeo, 36 (2010): 467-495.

2 Reglamento (UE) 1219/2012 del Parlamento Europeo y del Consejo, de 12 de diciembre de 2012 por el que se establecen disposiciones transitorias sobre los acuerdos bilaterales de inversión entre Estados miembros y terceros países, DOUE L 351, 20 diciembre de 2012.

${ }^{3}$ Reglamento (UE) 912/2014 del Parlamento Europeo y del Consejo, de 23 de julio de 2014, por el que se establece un marco para gestionar la responsabilidad financiera relacionada con los tribunales de resolución de litigios entre inversores y Estados establecidos por acuerdos internacionales en los que la Unión Europea sea parte, DOUE L 257, 28 agosto de 2014.

4 «Investment», European Commission. http://ec.europa.eu/trade/policy/accessing-markets/investment/, acceso el 23 de junio de 2016. 
es en este último contexto donde se está produciendo un intenso debate sobre la conveniencia de incluir en los nuevos tratados que se firmen referencias al arbitraje como mecanismo de resolución de controversias. Y es que los Acuerdos de inversión suelen incorporar en su clausulado el consentimiento arbitral de los Estados contratantes respecto a las disputas de inversión que puedan surgir entre éstos y los inversores de la otra parte contratante, constituyendo por tanto, la base jurídica sobre la que se asienta la competencia de los árbitros. Por consiguiente, la atribución a la Unión Europea de la competencia para celebrar Acuerdos de inversión el art. 207 TFUE supone la irrupción de la misma en el ámbito del arbitraje de inversiones. ${ }^{5}$

El rechazo a los mecanismos tradicionales de resolución de controversias inversor-Estado es especialmente patente en algunos Estados Miembros y ciertos sectores de la sociedad civil. E incluso en el Parlamento Europeo, donde se hubieron de suspender las votaciones sobre la Asociación Transatlántica de Comercio e Inversión con Estados Unidos (en adelante, en sus siglas anglosajonas, TTIP) en junio de 2015 por la oposición de un número importante de sus miembros. ${ }^{6}$ En este contexto la Comisión Europea ha publicado un proyecto detallado de propuestas para el capítulo sobre inversiones destinado al TTIP y al acuerdo bilateral de libre comercio ya celebrado con Canadá (en adelante, CETA) que incluye la creación un Sistema de Tribunales de Inversión, en sustitución de los mecanismos tradicionales de resolución de controversias inversor-Estado. Queda por ver si el Sistema de Tribunales de Inversión es finalmente bienvenido por los EEUU en las negociaciones del TTIP. Además, el futuro de dicho Tratado ${ }^{7}$ y del Acuerdo

5 Iñigo Iruretagoiena Agirrezabalaga, «Competencia de la Unión Europea en materia de inversiones extranjeras y sus implicaciones en el arbitraje inversor-Estado». Arbitraje, Revista de arbitraje comercial y de inversiones, 4/ 1 (2011): 117-136.

${ }^{6}$ EP vote and debate on TTIP recommendations postponed: what's next?, European Parliament. http://www.europarl.europa.eu/us/en/news_events/news/news_2015/news_ june_2015/ttip_recommendations.html, acceso el 23 de junio de 2016.

7 Una de las primeras adoptadas por el Presidente de los Estados Unidos, Donald Trump, fue declarar la retirada del Acuerdo Transpacífico de Cooperación Económica (TPP), habiéndose opuesto públicamente a la celebración de nuevos tratados comerciales. En la Unión Europea, la Comisión se comprometió a concluir las negociaciones del TTIP antes de finalizar el 2016, pero en Estados miembros como Francia y Alemania políticos destacados han anunciado el fracaso de las negociaciones del TTIP. «Trump and Clinton's free trade retreat: a pivotal moment for the world's economic future», The Guardian, 20 de agosto de 2016, último acceso el 14 de octubre de 2016, https://www theguardian.com/us-news/2016/aug/20/trumpclinton-free-trade-policies-tpp ; «TTIP has failed - but no one is admitting it, says German Vice-Chancellor Sigmar Gabriel», Independent, 28 agosto 2016, último acceso 14 de octubre de 2016, www.independent.co.uk/news/world/europe/ttip-trade-deal-agreement-failed-brexitlatest-news-eu-us-germany-vice-chancellor-a7213876.html. 
con Canadá parecen estar pendiente de un hilo. ${ }^{8}$ Pero, en cualquier caso y, como requisito inicial, el modelo de Tribunal de Inversiones propuesto debe ser conforme con los ordenamientos jurídicos de las partes intervinientes. Sin embargo, dicha cuestión ha pasado prácticamente desapercibida para la Comisión.

Este trabajo se propone analizar en las siguientes líneas la propuesta del Sistema de Tribunales de Inversión y su compatibilidad desde el punto de vista del Derecho europeo. En último término permitirá formular una reflexión más general sobre su viabilidad como método alternativo de resolución de conflictos inversor-Estado, distinto e independiente del arbitraje de inversiones, mecanismo cuya conformidad con el Derecho europeo ya ha sido cuestionada. ${ }^{9}$

\section{Las particularidades del arbitraje de inversiones como método de resolución de conflictos. Críticas a su actual configuración}

La propuesta del Sistema de Tribunales de Inversión parte de un enfoque distinto e innovador de la Unión Europea respecto de la protección de la inversión y la resolución de conflictos entre inversores extranjeros y Estados, los denominados mecanismos ISDS (por sus siglas anglosajonas, Investor-State Dispute Settlement). Como se examinará en los apartados que siguen, la propuesta pretende la sustitución del arbitraje de inversiones por un sistema judicial (Investment Court System) estructurado en dos niveles, uno de primera instancia y otro de apelación. Ello no ha hecho sino reavivar el debate doctrinal sobre la legitimidad del arbitraje de inversiones y su necesidad de reforma.

8 Tras su veto inicial al CETA, el Parlamento de Valonia finalmente rectificó y permitió su aprobación a nivel europeo. El 15 de febrero de 2017 el Parlamento Europeo dio su visto bueno al CETA, pero tal como la Comisión Europea declaró el pasado 5 de julio de 2016, dicho acuerdo tiene una naturaleza mixta por lo que no solo basta la aprobación del Consejo y del Parlamento Europeo sino que necesita la ratificación de al menos 36 parlamentos nacionales y provinciales de los Estados miembros. En cualquier caso, puede ser provisionalmente aplicado, excluyendo las disposiciones de protección de inversiones, a la espera del voto de los Parlamentos de los Estados miembros, Propuesta de Decisión del Consejo relativa a la aplicación provisional del Acuerdo Económico y Comercial Global entre Canadá, por una parte, y la Unión Europea y sus Estados miembros, por otra COM (2016) 470 final, 5 julio de 2016, <https://ec.europa.eu/transparency/regdoc/rep/1/2016/ ES/1-2016-470-ES-F1-3-ANNEX-12.PDF>.

${ }^{9}$ Inge Govaere, TTIP and Dispute Settlement: Potential Consequences for the Autonomous EU Legal Order, Research Papers in Law, 1/2016, Department of Legal Studies, College of Europe, www.hdl.handle.net/1854/LU-8031969, acceso el 17 de mayo de 2017. 


\section{El arbitraje de inversiones}

El arbitraje de inversiones surge con especial vigor a mediados del siglo XX como mecanismo de resolución de conflictos para proteger la seguridad jurídica del inversor extranjero ante los riesgos políticos de cambios normativos y frente a la posible falta de neutralidad e imparcialidad de los jueces y tribunales domésticos del Estado receptor de la inversión, bajo el contexto de un marco jurídico neutral, el derecho internacional de inversiones, adaptado a los contenciosos entre inversores extranjeros y Estados, y con base en los Tratados Bilaterales o Multilaterales de Inversión..$^{10}$ En realidad estamos ante instrumentos de control del respeto por parte de los Estados de la legalidad en el ámbito económico, del cumplimiento por parte del Estado de sus obligaciones internacionales. Y esta protección, que el inversor extranjero antes no tenía, ha hecho que proliferen las cláusulas compromisorias en los Tratados Bilaterales y Multilaterales de inversión. ${ }^{11}$

Aunque presenta una vinculación estrecha con el arbitraje comercial internacional, el arbitraje de inversiones posee características propias, como la de ser un arbitraje sin vínculo contractual, el reconocimiento de daños y perjuicios como consecuencia del incumplimiento o la ejecutabilidad directa de algunos laudos. En efecto, el arbitraje de inversiones, al reposar en un tratado internacional suscrito entre el Estado receptor de la inversión y el Estado de la nacionalidad del inversor, ha sido caracterizado, en términos generales, como un «arbitraje sin vínculo contractual»..$^{12}$ Se trata un procedimiento arbitral de carácter internacional y mixto, esto es, que otorga legitimación activa al inversor para solicitar un arbitraje de inversiones contra el Estado receptor como consecuencia de la violación del Tratado de Inversión, e incluso de un incumplimiento contractual en virtud de una cláusula de cobertura o paraguas (umbrella clause) ${ }^{13} \mathrm{El}$ consentimiento del Estado es general porque no se limita a un inversor específico, proyecto de inversión, disputa o serie de conflictos derivados de un evento determinado. En cambio, el consentimiento autoriza la iniciación de un arbitraje obligatorio por parte de cualquier miembro de una clase indeterminada de reclamantes

10 Enrique Fernández Masiá, «Arbitraje Inversor-Estado: de "Bella Durmiente" a "León en la jungla"». Revista electrónica de estudios internacionales (REEI), 26 (2013).

11 Conferencia de las Naciones Unidas sobre Comercio y Desarrollo, http:// investmentpolicyhub.unctad.org/ISDS/FilterByApplicableIia, acceso el 23 de junio de 2016.

12 José Carlos Fernández Rozas, «Internacionalismo vs Mercatorismo en la Especialización del Arbitraje Internacional», Arbitraje, Revista de Arbitraje Comercial y de Inversiones, 5/ 1 (2012): 37-90, 70.

13 Iñigo Iruretagoiena Agirrezabalaga, «Contract claims y treaty claims: relación entre las cláusulas umbrella y los acuerdos contractuales de atribución de competencia exclusiva». Arbitraje, Revista de Arbitraje Comercial y de Inversiones, $3 / 3$ (2010): 797-811. 
potenciales en relación con una muy amplia gama de conflictos, lo que ha llevado a comparar estas cláusulas compromisorias, con la emisión de un «cheque en blanco que se puede hacer efectivo por una cantidad incierta, en una fecha futura, aunque todavía desconocida.» ${ }^{14}$

Las cláusulas arbitrales de muchos Tratados de Inversión permiten al inversor elegir entre dos o más métodos de resolución de conflictos, siendo el foro más común el Centro Internacional de Arreglo de Diferencias relativas a Inversiones (en adelante, CIADI), que es una institución del Banco Mundial con sede en Washington creado como consecuencia del Convenio sobre Arreglo de Diferencias Relativas a Inversiones entre Estados y Nacionales de Otros Estados que entró en vigor en 1966. Todos los Estados Miembros de la UE, a excepción de Polonia, son parte de este Convenio. ${ }^{15} \mathrm{El}$ régimen de arbitraje del CIADI es aplicable a la resolución de disputas entre nacionales de Estados Contratantes del CIADI y otros Estados Contratantes del CIADI, donde los primeros han realizado una inversión. Se trata de un arbitraje realmente deslocalizado, en el sentido de que está sujeto a los preceptos del Convenio CIADI y normas que son totalmente independientes de cualquier derecho estatal. Pues bien, los laudos arbitrales que se dicten son directamente ejecutables en los Estados Contratantes del CIADI, estando los recursos limitados a un solo mecanismo de revisión del procedimiento en el mismo seno del CIADI. ${ }^{16}$ Otros foros ampliamente aceptados en el arbitraje de inversiones, aunque en menor medida, son los tribunales ad-hoc siguiendo el Reglamento de arbitraje de la CNUDMI (en adelante, UNCITRAL) ${ }^{17}$ o el Instituto de Arbitraje de la Cámara de Comercio de Estocolmo. ${ }^{18}$ En términos procedimentales, los arbitrajes de inversión realizados en estos últimos foros son distintos en muchos aspectos de los arbitrajes CIADI, pues los laudos necesitan el respaldo de los mecanismos tradicionales de ejecución, tales como Convención sobre el Reconocimiento y la Ejecución de las Sen-

${ }^{14}$ Gus Van Harten y Martin Loughlin, «Investment Treaty Arbitration as a Species of Global Administrative Law». The European Journal of International Law, 17/1 (2006): 121150,126 ss.

15 https://icsid.worldbank.org/apps/ICSIDWEB/icsiddocs/Documents/Lista\%20de\%20 Estados\%20Contratantes\%20y\%20Signatarios\%20de1\%20Convenio-\%20Latest.pdf , a 12 de abril de 2016,

16 Art. 52 del Reglamento de Arbitraje del Convenio del CIADI.

17 Clyde Croft, Christopher Kee y Jeff Waincymer, «A Guide to the UNCITRAL Arbitration Rules». Cambridge: Cambridge University Press (2013).

18 Karl Guterstam, et al., «SCC Arbitration Rules». Mistelis (ed.) Concise International Arbitration, Segunda Edición, Kluwer Law International (2015): 709 y ss; Nils Eliasson, «Stockholm as a Forum for Investment Arbitration». Martin Wallin, et al. (eds.) «International Arbitration in Sweden: A Practitioner's Guide». Kluwer Law International (2013): 2552. 
tencias Arbitrales Extranjeras (Convención de Nueva York de 1958). Así pues, los laudos fuera del régimen del CIADI pueden ser anulados bajo los mismos supuestos que los laudos de arbitraje comercial y quedan sujetos a la apreciación de jueces y tribunales nacionales. ${ }^{19}$

Si bien el procedimiento arbitral es esencialmente el mismo que en el arbitraje comercial, incluyendo la constitución del tribunal, principios aplicables al proceso, emisión del laudo etc., la controversia se dirime conforme a un tratado internacional sometido al derecho internacional que cuenta con principios propios destinados a proteger al inversor, como como el de trato justo y equitativo o los del trato nacional, trato de nación más favorecida o plena protección y seguridad ${ }^{20}$ Se trata de principios e instituciones creados al amparo de una jurisprudencia arbitral cada vez más amplia ya que la protección del inversor viene recogida normalmente en términos abiertos y elásticos, por lo que en muchos casos los árbitros deben actuar como pseudolegisladores. En la realización de esta tarea los árbitros se suelen remitir a la redacción literal del Tratado de Inversión aplicable, así como sobre la orientación que el precedente arbitral puede proporcionar, jugando éste un papel más prominente que en el arbitraje comercial. En cualquier caso, los tribunales arbitrales no están obligados por el principio de stare decisis, es decir, no tienen ningún deber de decidir el caso basándose en el contenido de las decisiones anteriores sobre temas similares; por lo tanto, existe un riesgo potencial de inconsistencia de los laudos arbitrales, que podrían decidir casos análogos diferentemente.

\section{El debate sobre la legitimidad del arbitraje de inversiones}

Es innegable que el arbitraje de inversiones resulta muy atractivo para los inversores extranjeros, quienes encuentran a su disposición un ámbito en el que los Estados se despojan de sus privilegios y litigan «entre iguales» con las empresas privadas para resolver sus controversias. Desde otra perspectiva, sin embargo, ha sido objeto de muchas críticas que cuestionan la legitimidad del arbitraje de inversiones precisamente por situar en un

19 Albert Jan Van Der Berg (ed.), «New Horizons in International Commercial Arbitration and Beyond». ICCA Congress Series Set (Book 12), Kluwer Law International (2005): 188 y ss.

${ }^{20}$ Enrique Fernádez Masiá, «Atribución de competencia a través de la cláusula de nación más favorecida: lecciones extraídas de la reciente práctica arbitral en materia de inversiones extranjeras». Revista electrónica de estudios internacionales (REEI), 13 (2007) http://www.reei.org/index.php/revista/num13/articulos/atribucion-competencia-travesclausula-nacion-mas-favorecida-lecciones-extraidas-reciente-practica-arbitral-materiainversiones-extranjeras. 
mismo plano intereses de naturaleza estrictamente privada con intereses de carácter general.

Casi todas las críticas apuntan a la tensión resultante de la fusión en el arbitraje de inversiones de fuentes del Derecho internacional clásico con un arbitraje de estilo comercial para resolver lo que son esencialmente controversias públicas acerca de la conformidad del ejercicio de la potestad normativa y administrativa del Estado de acogida bajo la óptica del Derecho internacional. ${ }^{21}$ Se aduce que el arbitraje de inversiones es una privatización intolerable de la justicia puesto que las controversias de inversión no se originan en una relación de reciprocidad sino en un contexto regulatorio. ${ }^{22} \mathrm{~A}$ este respecto, la resolución de este tipo de controversias se asemeja más al control judicial de la actividad de la Administración pública que al arbitraje comercial, donde solo se atiende a los intereses de las partes.

Ciertamente, al igual que en arbitraje comercial, son las partes quienes deciden el nombramiento de los árbitros, quienes pueden actuar como abogados en otras controversias y provocar con ello conflictos de interés, reales o aparentes. Además, la naturaleza ad-hoc de la designación arbitral puede llegar a percibirse como un incentivo económico para que se multipliquen los conflictos y las demandas de arbitraje.

La naturaleza privada del arbitraje de inversiones se manifiesta además, en su poca transparencia, que queda en mano de lo que decidan las partes, sobre todo los arbitrajes UNCITRAL, que son confidenciales. ${ }^{23}$ No así las controversias decididas en el régimen del CIADI, que publica todos sus casos. Pero a menudo las disputas se acaban resolviendo amistosamente en hoteles, a puerta cerrada, sin que se hagan públicos los documentos que reflejan los acuerdos. Esta opacidad se considera intolerable cuando se trata de controversias que implican cuestiones de interés público legítimo como el control y prohibición de sustancias nocivas, la protección de bienes culturales etc. que requieren en todo caso una supervisión pública. ${ }^{24}$

21 Josefa Cantero Martínez, «Arbitraje internacional de inversiones y «derecho a regular» de los estados: el nuevo enfoque comunitario en la negociación del TTIP». Revista Española de Derecho Europeo, 58 (2016): 13-45.

${ }^{22}$ Susan Franck, «The Legitimacy Crisis in Investment Treaty Arbitration: Privatizing Public International Law through Inconsistent Decisions». Fordham Law Review, 73 (2005): 1521-1625, <www.ir.lawnet.fordham.edu/flr/vol73/iss4/10>.

${ }^{23}$ Enrique Fernádez Masiá, «¿Es compatible la confidencialidad con el arbitraje en inversiones extranjeras?: Hacia una mayor transparencia y participación de terceros en los procedimientos arbitrales inversor-Estado». Revista vasca de derecho procesal y arbitraje $=\mathrm{Zu}-$ zenbide prozesala ta arbitraia euskal aldizkaria, 19/1 (2007): 1-14.

${ }^{24}$ Stephan Schill, «Crafting the International Economic Order: The Public Function of Investment Treaty Arbitration and Its Significance for the Role of the Arbitrator». Leiden Journal of International Law, 23 (2010): 401-430, 412. 
A todas las críticas anteriores se añade la complejidad de los procedimientos, la falta de consistencia de soluciones,$^{25}$ el riesgo de enfriamiento regulatorio ${ }^{26}$ y la existencia de un mecanismo externo y paralelo al sistema judicial estatal, vetado a los inversores nacionales y de facto, por su elevado coste, a las pequeñas y medianas empresas. ${ }^{27}$

\section{Propuestas de reforma}

Como reacción a las críticas descritas anteriormente se han planteado una serie de reformas materiales y de carácter procesal, sobre todo desde instancias doctrinales, aunque también de la práctica arbitral, al objeto de inspirar al legislador en la renovación del sistema de arreglo de diferencias inversor-Estado.

Desde un plano sustantivo, se ha apuntado a que la resolución de las controversias de inversión ha de tener necesariamente en cuenta las implicaciones de carácter público e impregnar las motivaciones del adjudicador con razonamientos dirigidos no solamente a las partes sino a terceros interesados (otros inversores, otros Estados) y a la opinión pública en general. ${ }^{28}$ Desde este punto de vista se propone, junto a una mayor precisión en definición de los estándares de protección de los inversores extranjeros ${ }^{29}$ la creación de un Derecho administrativo global de inversiones, una suerte de lex mercatoria publica, ${ }^{30}$ que tenga en cuenta las particularidades del derecho de inversiones y equilibre todos los intereses en presencia.

Desde un plano procesal, algunos tribunales arbitrales, motivados por la reforma de las reglas del CIADI en 2006, han reaccionado a algunas de las críticas ajustando el procedimiento en un mayor grado a consideraciones de derecho público como la transparencia y la aceptación de la intervención de amicus curiae. ${ }^{31}$ En este contexto es relevante mencio-

25 Susan Franck, op.cit., nota 22.

26 Vid. infra, 5.3.

27 Josefa Cantero Martínez, op .cit., nota 21.

28 Stephan, Schill, op .cit, nota 24.

29 Jan Kleinheisterkamp, «Financial Responsibility in European International Investment Policy». International and Comparative Law Quarterly, 63 (2014): 449-476, 471.

30 Término mencionado en Caroline Foster, «A New Stratosphere? Investment Treaty Arbitration as Internationalized Public Law». International and Comparative Law Quarterly, 64 (2015): 461-485, 465, en referencia a las tesis de Stephan Schill.

31 Ciaran Cross y Christian Schliemann-Radbruch, «When Investment Arbitration Curbs Domestic Regulatory Space: Consistent Solutions through Amicus Curiae Submissions by Regional Organisations». Law and Development Review, 6/ 2 (2013): 67-110. 
nar la adopción en 2013 del Reglamento de la CNUDMI sobre la Transparencia en los Arbitrajes entre Inversionistas y Estados en el Marco de un Tratado junto con la aprobación de un nuevo artículo, el artículo 1, párrafo 4, del Reglamento de Arbitraje de la CNUDMI (según el texto revisado de 2010). El Reglamento sobre Transparencia introduce un grado importante de publicidad de las actuaciones arbitrales, estableciendo, entre otras cosas, la divulgación pública de los laudos y otros documentos clave (artículos 2 y 3), determinando el carácter público de las audiencias (artículo 6) y admitiendo la presentación de escritos por terceros y partes en el Tratado que no sean litigantes (artículos 4 y 5). El Reglamento sobre Transparencia se aplica automáticamente a los arbitrajes entre inversionistas y Estados entablados, en virtud del Reglamento de Arbitraje de la CNUDMI, de conformidad con un tratado que establezca la protección de las inversiones o los inversionistas celebrado el 1 de abril de 2014 o después de esa fecha, a menos que las partes en el tratado hayan acordado otra cosa (artículo 1.1). Respecto a los arbitrajes entablados de conformidad con un tratado celebrado antes del 1 de abril de 2014, el Reglamento sobre Transparencia solamente se aplica si las partes litigantes en un arbitraje convienen en su aplicación respecto de ese arbitraje; o cuando las partes en el tratado o, en el caso de un tratado multilateral, el Estado del demandante y el Estado demandado han convenido en su aplicación después del 1 de abril de 2014. A este respecto, la Convención de las Naciones Unidas sobre la Transparencia en los Arbitrajes entre Inversionistas y Estados en el Marco de un Tratado (Convención de Mauricio) adoptada el 10 de diciembre de 2014, es un instrumento para obtener el consentimiento de las partes en los alrededor de 3000 tratados celebrados antes de la adopción del Reglamento sobre Transparencia. ${ }^{32}$ Dieciocho países han firmado la Convención, incluyendo los Estados Unidos, el Reino Unido, Canadá, Suecia, Finlandia y Alemania. Hasta ahora sólo Canadá y Mauricio lo han ratificado, pero una vez se obtengan tres ratificaciones, entrará en vigor.

El riesgo de inconsistencia en las decisiones también está presente como uno de los problemas a corregir, aunque los intentos de establecer un mecanismo de apelación en el CIADI no han llegado a buen puerto. Ello entronca con la propuesta de creación de un Tribunal Internacional de Inversiones que aporte consistencia y garantice la neutralidad e imparcialidad de las decisiones en las controversias inversor-Estado que lleva reali-

32 Stephan Schill, «The Mauritius Convention on Transparency». The Journal of World Investment \& Trade, 16/2 (2015): 201-204; James Fry, «Towards a New World for InvestorState Arbitration through Transparency». New York University Journal of International Law and Politics, 48 (2016): 796-865. 
zando desde hace algún tiempo algún sector doctrinal. ${ }^{33}$ Precisamente esta postura doctrinal ha cobrado recientemente especial importancia por ser el mecanismo de resolución de controversias inversor-Estado por el que aboga la Comisión Europea y que ha incluido en el Borrador de la posición europea en la última ronda negociadora del TTIP (en adelante, Borrador TTIP) (34 $^{34}$ y también forma parte del CETA ${ }^{35}$ y del Acuerdo de Libre Comercio con Vietnam. ${ }^{36}$

\section{Hacia un Tribunal de Inversiones en la Unión Europea}

Como ya se ha apuntado, con la entrada en vigor del Tratado de Lisboa en 2009 la Unión Europea ha adquirido la competencia exclusiva en materia de inversiones extranjeras directas (art. 207 TFUE), convirtiéndose junto a la política comercial común en uno de los principales pilares de la acción exterior de la misma. ${ }^{37}$ Esta circunstancia ha hecho que la Unión Europea haya interpretado esta nueva competencia como una oportunidad para intentar un tratamiento comprensivo de los temas de comercio e inversión a nivel europeo y para proponer una reforma profunda del sistema tradicional de protección de inversiones y de los mecanismos de resolución de controversias inversor-Estado. ${ }^{38}$ Como idea subyacente destaca el desafío de alcanzar un equilibrio entre la protección de la inversión y la potestad regulatoria de la Unión Europea y de los Estados Miembros, necesaria para la realización de políticas públicas y sobre todo, poner en pie un sistema de resolución de controversias justo e independiente. ${ }^{39}$

${ }^{33}$ Gus Van Harten, «A Case for an International Investment Court». Society for International Economic Law, Online Proceedings, Working Paper, 22/08, http://www.ssrn.com/link/ SIEL-Inaugural-Conference.html.

${ }^{34} \mathrm{http} / / /$ trade.ec.europa.eu/doclib/docs/2015/november/tradoc_153955.pdf.

$35 \mathrm{http} / / /$ ec.europa.eu/trade/policy/in-focus/ceta/ceta-chapter-by-chapter/index_es.htm.

$36 \mathrm{http} / / /$ trade.ec.europa.eu/doclib/press/index.cfm?id=1437.

${ }^{37}$ Luis Miguel Hinojosa Martínez, «El alcance de la competencia exterior europea en materia de inversiones». Revista de Derecho Comunitario Europeo, 52 (2015): 871-907.

${ }^{38}$ El primer paso lo constituyó la Comunicación de la Comisión al Consejo, al Parlamento Europeo, al Comité Económico y Social Europeo y al Comité de la Regiones, titulada «Hacia una política global europea en materia de inversión internacional» de 7 de julio de 2010, COM (2010) 343 final, donde se establecen los objetivos y estrategias para una futura política europea sobre inversiones a través de negociaciones y celebración de Acuerdos con terceros países.

39 Investment in TTIP and beyond - the path for reform. Enhancing the right to regulate and moving from current ad hoc arbitration towards an Investment Court http://trade. ec.europa.eu/doclib/docs/2015/may/tradoc_153408.PDF , acceso el 23 de junio de 2016. 
La nueva visión de la Unión Europea respecto a las inversiones extranjeras ha sido introducida en los acuerdos bilaterales de libre comercio concluidos por la Unión Europea con Canadá, ${ }^{40} \operatorname{Singapur}^{41}$ y Vietnam ${ }^{42}$, así en como Borrador de la posición europea sobre el TTIP, incluyendo novedades en cuando al fondo (normas sobre protección de la inversión) $\mathrm{y}$ al procedimiento (mecanismos de resolución de controversias inversorEstado).

Respecto al fondo, en estos últimos acuerdos la Unión Europea ha reafirmado el derecho a regular, ${ }^{43}$ ha definido conceptos clave como «tratamiento justo y equitativo» $\mathrm{y}$ «expropiación indirecta» para prevenir abusos. Ello supone un avance respecto a la formulación tradicional de los tratados de inversión en los que la protección del inversor viene recogida normalmente en términos muy abiertos y elásticos. ${ }^{44}$ En cuanto al procedimiento, la Unión Europea ha incluido por primera vez un código de conducta arbitral que asegure los más altos estándares éticos y profesionales; un sistema de inadmisión temprana de demandas infundadas o frívolas; el principio de que el perdedor paga las costas del proceso y la prohibición de procedimientos paralelos ISDS-tribunales nacionales. ${ }^{45}$ Cabe mencionar la referencia expresa al Reglamento de la CNUDMI sobre la Transparencia. El nuevo modelo propuesto quiere ir incluso más allá del Reglamento de la CNUDMI, exigiendo que muchos documentos, incluyendo todas las actuaciones ante el Tribunal de Apelación, se hagan siempre públicos (por ejemplo, tal como recoge el art. 18 Borrador TTIP). Igualmente, se permite la presentación de escritos del tipo amicus curiae, con mayor acceso a la documentación procesal por parte de estos terceros (por ejemplo, el art. 23 Borrador TTIP). Con ello, el modelo planteado por la Comisión Europea

40 Iñigo Iruretagoiena Agirrezabalaga, «La firma del Acuerdo Económico y Comercial Global entre la Unión Europea y Canadá: un primer y decisivo paso hacia el establecimiento de un renovado marco legal para las inversiones extranjeras en el ámbito europeo y global». La Ley Unión Europea, 42 (2016).

41 «EU-Singapore Free Trade Agreement. Authentic text as of May 2015». European Commission. http://trade.ec.europa.eu/doclib/press/index.cfm?id=961, acceso el 11 de mayo de 2017.

42 «EU-Vietnam Free Trade Agreement: Agreed text as of January 2016». European Commission. http://trade.ec.europa.eu/doclib/press/index.cfm?id=1437, acceso el 11 de mayo de 2017.

43 Josefa Cantero Martínez., op.cit., nota 21.

${ }^{44}$ Roland Kläger, Fair and Equitable Treatment in International Investment Law, Cambridge: Cambridge University Press (2011): 21.

${ }^{45}$ La nueva visión de la Unión Europea se detalla en European Commission, EU Finalises Proposal for Investment Protection and Court System for TTIP, Press Release, Bruselas, 12 de noviembre de 2015, disponible en http://europa.eu/rapid/press-release_IP-15-6059_ en.htm. 
parece tener en cuenta que la resolución de controversias inversor-Estado trasciende a los intereses de las partes implicadas.

Pero sobre todo, la Unión Europea ha apostado por un nuevo mecanismo para la resolución de controversias inversor-Estado, un «Sistema de Tribunales de Inversión» (Investment Court System) con el objetivo de garantizar la coherencia y previsibilidad del sistema.

En un primer momento la Comisión Europea era partidaria de remitir al arbitraje de inversiones en los acuerdos concluidos post-Lisboa: «La relación entre el inversor y el Estado es una característica tan consolidada de los acuerdos de inversión que la ausencia de dicho mecanismo disuadiría a los inversores y haría perder atractivo a una economía con respecto a otras. Por estos motivos, los futuros acuerdos de la UE que incluyan protección de las inversiones deberían contener un mecanismo de resolución de litigios entre el inversor y el Estado». ${ }^{46} \mathrm{Sin}$ embargo, en las negociaciones del TTIP, se puso de manifiesto la reacción contraria de una parte importante de la opinión pública europea ${ }^{47}$ apuntando a la posible pérdida de derechos sociales, laborales y medioambientales como consecuencia de la liberalización de mercados y armonización de legislaciones, pero centrando gran parte de las críticas en el sistema de resolución de disputas entre los inversores y los Estados. Las críticas incidían en muchos de los argumentos doctrinales que cuestionan la legitimidad del arbitraje de inversiones en tanto que discriminatorio y de naturaleza privada. ${ }^{48}$ En opinión de algunos, además, no era lógico remitir al arbitraje de inversiones en Acuerdos entre la UE y EEUU o Canadá, países que tienen un sistema judicial perfectamente capacitado para dirimir controversias con inversores extranjeros sobre la base de la legislación aplicable al resto de la sociedad. ${ }^{49}$

El rechazo de la opinión pública encontró el apoyo, entre otros, de políticos destacados en países como Francia o Alemania, ${ }^{50}$ del Comité Económico

46 Comunicación de la Comisión al Consejo, al Parlamento Europeo, al Comité Económico y Social Europeo y al Comité de las Regiones, Hacia una política global europea en materia de inversión internacional, COM (2010) 343 final (2010): 10.

47 Public Consultation on Modalities for Investment Protection and ISDS in TTIP, http://trade.ec.europa.eu/doclib/docs/2014/march/tradoc_152280.pdf, Casi 150,000 personas respondieron de las cuales un $97 \%$ mostró su rechazo al arbitraje de inversiones, https:// euobserver.com/opinion/132504, acceso el 28 de junio de 2016.

${ }_{48}$ Behind closed doors; Investment, arbitration and secrecy, The Economist, 25 abril 2009 , http://www.economist.com/node/13527961, acceso el 28 de junio de 2016. Los movimientos sociales de rechazo al TTIP tienen fuerte presencia también en el ciberespacio. http://www. noalttip.org/que-es-el-ttip/\#51; https://stop-ttip.org/es/, acceso el 28 de junio de 2016.

$49 \mathrm{http} / / / \mathrm{www} . \mathrm{s} 2$ bnetwork.org/statement-isds-ics/, acceso el 28 de junio de 2016.

50 Cécile Barbière, «France and Germany to form united front against ISDS», Euractiv.com, http://www.euractiv.com/section/trade-society/news/france-and-germany-to-formunited-front-against-isds/, acceso el 28 de junio de 2016. 
y Social, quien en su dictamen de 27 de mayo de 2015 sugirió la introducción, entre otras reformas, un mecanismo de apelación y un tribunal internacional multilateral de inversiones a largo plazo $^{51}$ y del Parlamento Europeo quien, tras aplazar una votación al respecto al TTIP por falta de consenso, planteó en su sesión de 8 de julio de 2015 reemplazar el arbitraje privado previsto por el mecanismo ISDS por un nuevo sistema judicial, gestionado por jueces nombrados de manera pública y sujetos a reglas de control y transparencia. ${ }^{52}$ Precisamente el Parlamento Europeo ha jugado un papel crucial en el cambio de posición de la Comisión Europea respecto al arreglo de controversias inversor-Estado. Ello propiciado en gran medida porque la política comercial común se rige por el procedimiento legislativo ordinario (art. 207.2 TFUE), lo que implica que el Parlamento Europeo ha de dar su consentimiento como requisito previo a la conclusión de los Acuerdos. La posibilidad de veto ha influenciado, por tanto, las decisiones de la Comisión. ${ }^{53}$

Así pues, la Comisión Europea a fin de neutralizar las críticas vertidas en el sistema tradicional de ISDS, modificó su posición inicial lanzando el 16 de septiembre de 2015 un proyecto detallado de propuestas para el capítulo sobre inversiones destinado al TTIP,${ }^{54}$ que incorporaba la propuesta de creación de un Sistema de Tribunales de Inversión, cuyas características más destacables son su permanencia y la introducción de un recurso de apelación. Este nuevo modelo fue con posterioridad introducido en el Acuerdo de Libre Comercio con Vietnam y en la revisión del CETA que tuvo lugar en febrero de 2016. Justamente el CETA es el primer Acuerdo en el que el nuevo mecanismo para el arreglo de controversias inversor-Estado se ha materializado, incluyéndose en el texto final firmado el 30 de octubre de 2016 entre la UE y Canadá. No obstante, las disposiciones de protección de inversiones, entre las que se encuentran las referentes al Sistema de Tribunales de Inversión, han sido excluidas de la aplicación provisional del Acuerdo, a la espera del voto de los Parlamentos de los Estados miembros. ${ }^{55}$

${ }^{51}$ REX/411 Dictamen del Comité Económico y Social Europeo sobre la protección de los inversores y la resolución de controversias entre inversores y Estados en los acuerdos de la UE con terceros países en materia de comercio e inversión.

52 Resolución del Parlamento Europeo, de 8 de julio de 2015, que contiene las recomendaciones del Parlamento Europeo a la Comisión Europea relativas a las negociaciones de la Asociación Transatlántica de Comercio e Inversión (ATCI), Parlamento Europeo. http://www.europarl.europa.eu/sides/getDoc.do?pubRef=-//EP//TEXT+TA+P8-TA-20150252+0+DOC+XML+V0//ES, acceso el 28 de junio de 2016.

53 Davor Jančić, «The Role of the European Parliament and the US Congress in Shaping Transatlantic Relations: TTIP, NSA Surveillance, and CIA Renditions». Journal of Common Market Studies, Vol. 54, 4 (2016): 896-912, 902.

54 Transatlantic Trade and Investment Partnership. http://trade.ec.europa.eu/doclib/ docs/2015/november/tradoc_153955.pdf, acceso el 28 de abril de 2017.

55 Vid. supra, nota 9. 


\section{El Sistema de Tribunales de Inversión}

La estructura y principales características del Sistema de Tribunales de Inversión siguen unas pautas parecidas en el Borrador de la posición europea sobre el TTIP, en el CETA y en el Acuerdo con Vietnam, habiéndose analizado y evaluado con detalle, entre otros, por el Grupo de Trabajo sobre Tratados de Inversión del Comité de Arbitraje Internacional, de la sección de Derecho internacional de la American Bar Association, a cuyas conclusiones remitimos ${ }^{56}$ El objetivo este trabajo no es analizarlo exhaustivamente en tanto que mecanismo alternativo al arbitraje de inversiones, aunque a efectos de su posterior estudio desde la perspectiva del Derecho europeo, creemos oportuno explicarlo brevemente como sigue:

El Sistema de Tribunales de Inversión es un mecanismo permanente y a dos instancias compuesto por un Tribunal de Primera Instancia (Tribunal de Inversiones) y por un Tribunal de Apelaciones. El Tribunal estará conformado por 15 miembros (que no jueces o árbitros) designados conjuntamente por la UE y el gobierno de la otra parte, quienes nombrarán dos tercios de los mismos de la nacionalidad de cada una de las partes (5 nacionales de Estados Miembros de la UE y 5 de la otra parte); el restante tercio serán nacionales de terceros Estados. La designación se hará por un periodo de seis años, renovable una sola vez y debiendo hacerse entre profesionales que tengan unas cualificaciones comparables a aquellas que se exigen para formar parte de los tribunales nacionales o internacionales como puede ser el Tribunal Internacional de Justicia de la Haya o el Órgano de apelación de la Organización Mundial del Comercio.

Tal como ocurre en los tribunales nacionales e internacionales las partes no podrán elegir a los miembros del Tribunal y para el enjuiciamiento de cada caso concreto, se formará un tribunal compuesto de tres miembros, designados al azar, uno de la nacionalidad de cada una de las partes y un tercero de entre los nacionales de terceros Estados, que actuará como presidente. Las partes, sin embargo, podrán acordar que el Tribunal fuera unipersonal, siendo siempre en este caso el juez nacional de un tercer país. Según la Comisión, este sistema de designación de jueces al azar evitará cualquier riesgo de interferencia por parte de cualquiera de las partes en conflicto lo que supone un cambio fundamental respecto al arbitraje de inversiones que opera $a d$ hoc con árbitros designados por las partes. Una vez constituido el Tribunal, la controversia habrá de resolverse

56 Task Force Report on the Investment Court System Proposal, Investment Treaty Working Group of the International Arbitration Committee, American Bar Association Section on International Law, 14 octubre 2016, www.americanbar.org/aba.html . Respecto al Acuerdo con Canadá vid. Iñigo Iruretagoiena, op.cit., nota 40. 
en el plazo de 18 meses desde la presentación de la demanda actuando de acuerdo con las reglas procesales elegidas, ya fueran las del CIADI, las de UNCITRAL o cualesquiera otras.

Por su parte, el Tribunal de Apelaciones operará siguiendo los mismos principios que el Tribunal de Apelaciones de la OMC. Estará compuesto por seis miembros designados conjuntamente por la UE y la otra parte, de los cuales dos serían nacionales de la UE, dos de la otra parte y dos de terceros Estados, actuando estos últimos como Presidente y Vicepresidente de este órgano de apelación. Los miembros del Tribunal de Apelaciones también estarán sujetos a estrictos requisitos éticos y profesionales, siendo su mandato de seis años, renovables por otros seis. En opinión de la Comisión de esta forma se eliminará cualquier duda en cuanto a la corrección legal de las decisiones, proponiéndose, además, en el interés de los inversores y los Estados, límites estrictos de tiempo para asegurar una decisión rápida. Así, se establece un plazo estricto de 90 días para la presentación del escrito de apelación desde la emisión de la sentencia, contemplándose igualmente un plazo breve para la resolución de la controversia -180 días desde la notificación de la apelación, aunque sujeto a un periodo suplementario que nunca podrá superar conjuntamente con el anterior la cifra de los 270 días.

Un aspecto significativo de la propuesta de la Comisión es que prohíbe tanto a los miembros del Tribunal como a los miembros del Tribunal de Apelaciones actuar como abogados en otras disputas de inversión, hecho que reduce considerablemente el número de personas que podrían ser designadas como miembros del Sistema. Teniendo en cuenta que los mejores expertos en ejercicio ganan una media superior a los 7.000 euros al mes que establece el Borrador de TTIP como honorario de los miembros del Tribunal de Apelaciones, la lista de profesionales dispuestos a formar parte del Sistema se limitaría a académicos, antiguos jueces o abogados retirados. .7

La visión de la Unión Europea va más allá y tanto el Borrador del TTIP, el CETA y el Tratado de Libre Comercio EU-Vietnam incluyen el compromiso de aunar esfuerzos con otros socios comerciales para crear un Tribunal permanente y multilateral de inversiones con un mecanismo permanente de apelación, que conllevaría una utilización de recursos más eficiente y tendría más legitimidad. Por ello la Comisión Europea está actualmente colaborando con expertos de varias organizaciones internacionales en este campo, con el objetivo de reemplazar en un futuro el modelo bilateral de

57 Task Force Paper regarding the proposed International Court System (ICS) European federation for Investment Law and Arbitration, http://efila.org/wpcontent/uploads/2016/02/ EFILA_TASK_FORCE_on_ICS_proposal_1-2-2016.pdf, acceso el 28 de junio de 2016. 
Sistema de Tribunales de Inversión..$^{58}$ No está claro, sin embargo, cuál va a ser el modelo a seguir para multilateralizar el Sistema de Tribunales de Inversión. El modelo propuesto por la Comisión con jueces provenientes de la UE y Estados Unidos/Canadá/Vietnam a partes iguales y solo un tercio de jueces nacionales de terceros países no parece ser un modelo que pueda funcionar como punto de partida para la constitución de un Tribunal multilateral de inversiones. Además, los defectos percibidos en el sistema actual de resolución de controversias inversor-Estado como la dispersión de soluciones, inconsistencias etc. se derivan en parte de los más de 3.000 tratados bilaterales de inversión o tratados de libre comercio que están en vigor. El Tribunal multilateral, a menos que incluyese a todos los Estados parte de esos Tratados no cambiaría la situación de dispersión a nivel global.

En este punto podemos concluir que el Sistema de Tribunales de Inversión refleja el esfuerzo de la Comisión Europea por contrarrestar las críticas a los mecanismos tradicionales de arreglo de controversias inversor-Estado asegurando la coherencia de soluciones, mediante un Tribunal de Apelaciones y la permanencia del Sistema, a objeto de evitar potenciales conflictos de interés. Además, se ha intentado elevar el grado de publicidad de los procedimientos para garantizar un sistema transparente y equitativo y facilitar el acceso de los pequeños y medianos inversores a los mecanismos de ISDS. En este último punto, sin embargo, la solución propuesta por la Comisión no ha sido del todo satisfactoria, pues como se verá más adelante, no parece haber eliminado la percepción por gran parte de la opinión pública de que el Sistema de Tribunales de Inversión sigue constituyendo un privilegio de los inversores extranjeros, al margen del sistema judicial del Estado. .9

\section{Análisis del Sistema de Tribunales de Inversión desde la perspectiva del Derecho europeo}

Hasta la fecha la opinión pública y la academia se han centrado en un análisis de oportunidad y legitimidad del Sistema de Tribunales de Inversión, dejando prácticamente a un lado el análisis de los posibles escollos legales desde el punto de vista del Derecho de la UE. Dicha circunstancia no deja de sorprender, teniendo en cuenta la interpretación del Tribunal de Justicia de la Unión Europea respecto a la relación jurídica entre este y otros tribunales y órganos jurisdiccionales internacionales. De igual forma, cuestiones directamente relacionadas con el Derecho de la Unión Europea tales como la garantía

58 EU finalises proposal for investment protection and Court System for TTIP, European Commission.http://europa.eu/rapid/press-release_IP-15-6059_en.htm, a 11 de mayo de 2017.

59 Iñigo, Iruretagoiena, op .cit., nota 40. 
del principio de autonomía del ordenamiento jurídico europeo, la competencia exclusiva del TJUE para dirimir recursos por responsabilidad extracontractual o la exclusión del efecto directo en los acuerdos de comercio e inversión, requieren un análisis más exhaustivo que el realizado hasta el momento.

\section{La autonomía del ordenamiento jurídico de la UE}

El TJUE ha declarado en relación a la creación de un sistema unificado de resolución de litigios en materia de patentes (Dictamen $1 / 09)^{60}$ y a la Adhesión al Convenio Europeo de Derechos Humanos (Dictamen 2/13) ${ }^{61}$ la incompatibilidad con el Derecho europeo de instrumentos legales en los que otros órganos jurisdiccionales internacionales puedan poner en jaque los principios de autonomía y primacía y la competencia exclusiva del Tribunal de Justicia de la Unión Europea en la interpretación y aplicación del Derecho de la Unión. En efecto, el mencionado Dictamen 2/13 emitido por el Tribunal de Justicia de la Unión Europea sobre la adhesión de la Unión Europea al Convenio Europeo de Derechos Humanos (CEDH), reitera e incluso agudiza las reticencias expresadas anteriormente en los Dictámenes 1/9162, 1/0063 y 1/09, al sostener que la Unión Europea no podría acceder al CEDH, porque las competencias del Tribunal Europeo de Derechos humanos (TEDH) socavarían a las del TJUE, en contradicción con los Tratados constitutivos de la UE. ${ }^{64}$ Algunos de los principales argumentos en los que se basa este Dictamen son, resumiendo, los siguientes: ${ }^{65}$ a) Respeto a los principios de autonomía y primacía del Derecho de la UE y a la competencia exclusiva del TJUE para interpretar y aplicarlo (párrafo 184); b) Exigencia de preservar la com-

${ }^{60}$ Dictamen del Tribunal de Justicia de 8 de marzo de 2011 sobre la creación de un sistema unificado de resolución de litigios en materia de patentes - Tribunal europeo y comunitario de patentes, ECLI:EU:C:2011:123.

${ }^{61}$ Dictamen del Tribunal de Justicia de 18 de diciembre de 2014 sobre la Adhesión de la Unión Europea al Convenio Europeo para la Protección de los Derechos Humanos y de las Libertades Fundamentales, ECLI:EU:C:2014:2454.

${ }^{62}$ Dictamen del Tribunal de Justicia de 14 de diciembre de 1991 sobre la creación del Espacio Económico Europeo, ECLI:EU:C:1991:490.

63 Dictamen del Tribunal de Justicia de 18 de abril de 2002 sobre la creación del espacio Europeo Aéreo Común, ECLI:EU:C:2002:231.

${ }^{64}$ José Carlos Fernández Rozas, «La compleja adhesión de la Unión Europea al Convenio Europeo de Derechos Humanos y las secuelas del Dictamen 2/2013 del Tribunal de Justicia». La Ley Unión Europea, 23 (2014): 40-56.

${ }^{65}$ Ricardo Alonso García, «Análisis crítico del veto judicial de la UE al CEDH en el Dictamen 2/13, de 18 de diciembre de 2014». Papeles de Derecho Europeo e Integración Regional, WP IDEIR, 26 (2015), https://www.ucm.es/data/cont/docs/595-2015-11-25-Binder1. pdf, acceso el 10 de mayo de 2017. 
petencia exclusiva del Tribunal de Justicia de la UE de conformidad con el art. 344 TFUE para conocer las controversias entre Estados Miembros relativas a la interpretación o aplicación de los Tratados (párrafos 201-214); c) Necesidad de garantizar que ningún otro órgano jurisdiccional pueda decidir sobre la distribución de responsabilidad entre la UE y los Estados Miembros, así como determinar quién puede actuar como parte demandada en cualquier controversia relacionada con un presunto incumplimiento de una disposición de un acuerdo internacional (párrafos 215-235) y d) Obligación de evitar que la interpretación de una disposición del Derecho de la Unión, inclusive del derecho derivado, mediante un procedimiento de intervención previa del Tribunal de Justicia quede sujeta a la revisión del TEDH o de cualquier otro tribunal internacional (párrafos 236-248).

Los argumentos esgrimidos por el TJUE sobre la adhesión de la Unión Europea al Convenio Europeo de Derechos Humanos pueden ser extrapolables a otros campos, toda vez que se centran en la relación genérica entre el Derecho de la UE y el Derecho internacional, así como entre el TJUE y otros tribunales y órganos jurisdiccionales internacionales. Por ello, son de utilidad para analizar la legalidad del propuesto Tribunal Internacional de Inversiones desde la perspectiva del Derecho de la UE.

La doctrina ya ha avanzado que algunos obstáculos serían fácilmente salvables, como por ejemplo, la referencia al art. 344 TFUE, que solo se aplica a controversias entre los Estados Miembros ${ }^{66}$ dejando fuera a las controversias entre inversor-Estado, como las que serían objeto del Sistema de Tribunales de Inversión. ${ }^{67}$

También se ha afirmado que la necesidad de garantizar que ningún otro órgano jurisdiccional pueda decidir sobre la distribución de responsabilidad entre la UE y los Estados miembros, así como determinar quién puede actuar como parte demandada, objeto de regulación interna en la UE por el Reglamento sobre Responsabilidad Financiera, ${ }^{68}$ se puede solven-

${ }^{66}$ Philip Strik, «Shaping the Single European Market in the Field of Foreign Direct Investment». Oxford and Portland, Oregon: Hart Publishing (2014): 240 ss.

${ }^{67}$ Stephan Schill, «Editorial: Opinion 2/13 - The End for Dispute Settlement in EU Trade and Investment Agreements?». The Journal of World Investment \& Trade, 16 (2005): 379-388, 384; C. Hillion and R.A. Wessel, «The European Union and International Dispute Settlement: Mapping Principles and Conditions». M. Cremona, et al. (Eds.), «The European Union and International Dispute Settlement». Oxford: Hart Publishing (2017), https://www. utwente.nl/en/bms/pa/research/wessel/wessel118.pdf.

68 Reglamento (UE) No 912/2014 del Parlamento Europeo y del Consejo de 23 de julio de 2014 por el que se establece un marco para gestionar la responsabilidad financiera relacionada con los tribunales de resolución de litigios entre inversores y Estados establecidos por acuerdos internacionales en los que la Unión Europea sea parte (DOUE L 257/221 de 28 de agosto de 2014). 
tar incluyendo una norma al respecto en el Acuerdo de Inversión correspondiente. ${ }^{69}$ De hecho, el artículo 5.3 del Borrador TTIP presentada por la Comisión Europea en noviembre de 2015 establece que corresponde a la Unión Europea determinar quién va a actuar como demandado - si la Unión Europea o un Estado miembro de la Unión - debiendo informar al demandante en este sentido dentro de los 60 días siguientes a la recepción de la notificación de la intención de iniciar un procedimiento, quedando el Tribunal de Primera Instancia o el Tribunal de Apelaciones vinculados por dicha determinación (art. 5.6). Sin embargo, la solución propuesta por la Comisión no es del todo satisfactoria, pudiendo acarrear más problemas que soluciones. Por ejemplo, se puede dar el caso de que el Tribunal concluya que ha habido una violación de los derechos protegidos del inversor que da lugar a una indemnización, pero que no pueda conceder daños y perjuicios sobre la base de que el demandado no es responsable del daño sufrido. Además, como tanto el Tribunal de Primera Instancia como el de Apelaciones estarían obligados a seguir la determinación de la UE sobre quién es la parte demandada, la situación no podría ser resuelta. Y en esta misma línea, otra consecuencia evidente de la solución propuesta por la Comisión sería la importante limitación de las posibilidades de ejecución por parte del inversor, ya que si la UE determina que ella es el demandado apropiado en lugar de un Estado miembro, el Convenio del CIADI no sería de aplicación, al no ser la UE parte contratante del dicho Convenio, privando al inversor de la ejecutabilidad directa de la decisión prevista en el artículo 54 de dicho Convenio y obligándolo a seguir un proceso mucho más largo y más engorroso. ${ }^{70}$

Un obstáculo más difícil de superar es la salvaguarda los principios de autonomía y primacía del Derecho de la UE garantizando que ningún otro órgano jurisdiccional pueda vincular a la Unión Europea y a sus instituciones mediante una determinada interpretación del Derecho de la UE. Respecto a los mecanismos de ISDS la Comisión Europea ya alegó en su intervención como amicus curiae en Achmea c. Eslovaquia que el tribunal de arbitraje debía inhibirse en favor del TJUE porque los mecanismos de resolución de controversias inversor-Estado no eran compatibles con la

${ }^{69}$ Stephan Schill, «The proposed TTIP Tribunal and the Court of Justice: What Limits to Investor-State Dispute Settlement under EU Constitutional Law?». Verfassungsblog, http://verfassungsblog.de/the-proposed-ttip-tribunal-and-the-court-of-justice-what-limitsto-investor-state-dispute-settlement-under-eu-constitutional-law/, acceso el 19 de octubre de 2016.

${ }^{70}$ Louise Woods, «Fit for Purpose? The EU's Investment Court System». Kluwer Arbitration Blog, http://kluwerarbitrationblog.com/2016/03/23/to-be-decided/, acceso el 23 de marzo de 2016. 
competencia exclusiva del TJUE respecto a reclamaciones en las que ha de aplicarse la legislación comunitaria, aunque sólo fuera tangencialmente. ${ }^{71}$ El mismo argumento sería extrapolable al Sistema de Tribunales de Inversión y así, la Comisión Europea ha articulado mecanismos en su propuesta para mantener una separación total entre el DUE y el derecho de inversiones. Dichos mecanismos incluyen: a) limitar la competencia del Tribunal de Inversiones exclusivamente a demandas por posibles incumplimientos del tratado de inversión correspondiente, excluyendo cualquier violación del Derecho de la UE; b) considerar cualquier interpretación del derecho interno como cuestión accidental; c) limitar la consideración del derecho interno como una cuestión meramente fáctica y d) la declaración de que cualquier interpretación realizada por el Tribunal de Inversiones no vinculará en ningún caso a los tribunales nacionales. En efecto, los artículos 8.31, apartado 2 CETA o los artículos 13.3 y 13.4 Borrador TTIP, proclaman lo siguiente:

Art. 8.31, apartado 2 CETA: «El tribunal no será competente para determinar la legalidad de una medida que supuestamente constituya una violación del presente Acuerdo, de conformidad con el Derecho interno de una Parte. Para mayor seguridad, al determinar la compatibilidad de una medida con el presente Acuerdo, el tribunal podrá tener en cuenta, en su caso, el Derecho interno de una Parte como un elemento de hecho. Al hacerlo, el tribunal seguirá la interpretación predominante dada al Derecho interno por los órganos jurisdiccionales o las autoridades de dicha Parte, y cualquier sentido que el tribunal haya dado al Derecho interno no será vinculante para los órganos jurisdiccionales o las autoridades de dicha Parte.»

Art. 13.3 Borrador TTIP: "Para mayor certeza, [...] el derecho interno de los contendientes no será parte de la legislación aplicable. Cuando el Tribunal deba conocer el significado de una disposición de derecho interno de una de las partes como cuestión de hecho, deberá seguir la interpretación que prevalece de dicha disposición por los órganos jurisdiccionales o autoridades de esa parte». Art. 13.4: «Para mayor certeza, el significado dado a la legislación nacional hecha por el Tribunal no será obligatoria en los tribunales o las autoridades de cualquiera de las partes. El Tribunal no tendrá competencia para determinar la legalidad de una medida, que presuntamente constituye una violación de este acuerdo, de conformidad con el derecho interno de la parte contendiente». ${ }^{72}$

71 Achmea B.V. c. República Eslovaca, UNCITRAL, PCA Asunto Núm. 2008-13 laudo sobre competencia de 7 diciembre 2012, párr. 193, www.italaw.com/documents/EurekovSlovakRepublic AwardonJurisdiction.pdf.

${ }^{72}$ La traducción es mía. 
La solución propuesta para mantener el DUE y el derecho de inversiones totalmente separados no está exenta, sin embargo, de posibles influencias mutuas. Por ejemplo, el Tribunal de Inversiones habrá de limitarse a analizar si una medida concreta adoptada por la UE o un Estado miembro ha infringido o no el Acuerdo bilateral correspondiente, con independencia de que la medida en cuestión sea compatible o no con el Derecho de la UE. Dicha solución, se argumenta, permite establecer un mecanismo de resolución de controversias inversor-Estado al margen de la intervención del TJUE. ${ }^{73}$ Pero podemos pensar en situaciones donde el Tribunal de Inversiones tendría que analizar la legalidad de una medida interpretando el Derecho de la UE, como a la hora de dirimir si un contrato fue terminado legalmente o la legalidad de una modificación regulatoria, para poder descartar si persisten derechos susceptibles de expropiación. Teniendo en cuenta, además, que dentro de la nueva visión de la UE respecto a su política comercial se han definido conceptos clave como «tratamiento justo y equitativo» y «expropiación indirecta» en relación con el derecho a regular - se entiende que legalmente - de la UE, más tarde o más temprano podrían sucederse interpretaciones paralelas y potencialmente divergentes del Derecho europeo.

Tanto el CETA como el Borrador TTIP incluyen un mecanismo adicional de protección de la autonomía y primacía del DUE mediante el que se establece que toda interpretación del derecho interno ha de ser tratada como una cuestión simplemente incidental en relación al asunto principal de violación de los derechos sustantivos de los inversores conforme al Acuerdo correspondiente. ${ }^{74}$ En otras palabras, el Tribunal de Inversiones, no podrá decidir a título principal que el demandado infringió la legislación interna. Pero la potencial existencia de interpretaciones paralelas y potencialmente del DUE, aún con carácter incidental, todavía sería posible.

Para limitar aún más el efecto de superposición de interpretaciones del DUE, tanto el CETA como el Borrador TTIP dejan claro que cualquier interpretación del derecho interno por parte del Tribunal de Inversiones no será vinculante para los tribunales o las autoridades de cualquiera de las partes y solo será considerada como cuestión meramente fáctica. ${ }^{75}$ Esta posición parece seguir el dictado del Tribunal Permanente de Justicia Inter-

73 Stephan Schill, «Editorial: Opinion 2/13», op.cit., p. 387.

74 Vid. Art. 13.4 Borrador TTIP.

75 Art. 13.3 Borrador TTIP: «Where the Tribunal is required to ascertain the meaning of a provision of the domestic law of one of the Parties as a matter of fact [...]»; Art. 8:31, sec. 2 CETA: «Para mayor seguridad, al determinar la compatibilidad de una medida con el presente Acuerdo, el tribunal podrá tener en cuenta, en su caso, el Derecho interno de una Parte como un elemento de hecho.» 
nacional según el cual «Desde el punto de vista del derecho internacional y de la Corte que es su órgano, las leyes municipales son simplemente hechos que expresan la voluntad y constituyen las actividades de los Estados, de la misma manera como lo hacen las decisiones judiciales o las medidas administrativas». ${ }^{76}$ Además, las normas procesales internas generalmente consideran el derecho extranjero como una cuestión de hecho. ${ }^{77}$ Pero cabe preguntarse si esta tentativa de la Comisión destinada a aislar el derecho nacional, incluyendo la legislación comunitaria, del derecho de inversiones, destacando que «para mayor certeza» el derecho interno ha de ser considerado como cuestión de hecho, tendría consecuencias reales en la práctica. La forma normal de juzgar es aplicando la ley a los hechos subyacentes; no es totalmente lógico aplicar hechos a hechos. Los tribunales de arbitraje y otras cortes internacionales tienen a menudo que interpretar y aplicar el derecho interno y excepto en lo que se refiere a la obligación de aplicarlo o no de oficio, no está claro que su tratamiento como cuestión fáctica cambie el proceso de razonamiento del Tribunal en cuestión. ${ }^{78}$ Según lo expresado por el Tribunal de SPP c. Egipto, el argumento de que «[...] el derecho municipal debe tratarse como un «hecho» no es útil. [Cuando] las partes están en desacuerdo fundamental en cuanto a lo que [una disposición de derecho interno] significa [...] el Tribunal debe interpretar [esa disposición] y determinar sus efectos jurídicos». ${ }^{79}$ En consecuencia, aunque en la propuesta de la Comisión se considere como cuestión puramente fáctica, la interpretación y aplicación del derecho nacional, incluyendo el DUE, que lleve a cabo Tri-

${ }^{76}$ La traducción es mía. Certain German Interests in Polish Upper Silesia (Germany v. Poland), (Merits) (1926) PCIJ, ser. A Núm.7, 19. Vid. NOLLKAEMPER, A., «The Role of Domestic Courts in the Case Law of the International Court of Justice», Chinese Journal of International Law, Vol. 5, 2006, pp. 301-322, p. 303.

77 En el Derecho español el principio iura novit curia no rige para el derecho extranjero. El art. 281.2 de la Ley 1/2000, de 7 de enero, de Enjuiciamiento Civil indica que: «También serán objeto de prueba la costumbre y el derecho extranjero. (...) El derecho extranjero deberá ser probado en lo que respecta a su contenido y vigencia, pudiendo valerse el tribunal de cuantos medios de averiguación estime necesarios para su aplicación». En la tradición y práctica del common law, el derecho extranjero es considerado como una cuestión puramente fáctica, Sussex Peerage Case, 11 Cl. \& Fin. 85, 8 Eng. Rep. 1034 (H.L. 1844) o la Regla 44.1 de las Normas Federales de Procedimiento Civil de los Estados Unidos. En países como Alemania, sin embargo, la regla general comúnmente aceptada es que el derecho extranjero ha de ser tratado como Derecho y no como hecho, art. 293 ZPO. Vid. HAUSMANN, R., «Pleading and Proof of Foreign Law - a Comparative Analysis,» The European Legal Forum, Vol. 1, 2008, pp. 1-14.

78 Jarrod Hepburn, CETA's New Domestic Law Clause, www.ejiltalk.org/cetas-newdomestic-law-clause. Acceso el 9 de agosto de 2016.

79 Southern Pacific Properties (Middle East) Limited v. Arab Republic of Egypt, ICSID Case No. ARB/84/3 www.italaw.com/cases/3300\#sthash.kfmsEyRu.dpuf (Decision on Jurisdiction, 58). Parafraseado en Jarrod Hepburn, CETA's New Domestic Law Clause, ibid. 
bunal de Inversiones puede llegar influir en la toma de decisiones y convertirse, en caso de reiteración, en una suerte de precedente.

La situación se agrava además por la circunstancia de que aunque el Tribunal de Inversiones habría de seguir la interpretación predominante del derecho interno establecida por los tribunales o autoridades de las parte firmantes del Acuerdo, no estaría directamente obligado a solicitar ni tendría competencia para someter al TJUE una cuestión prejudicial de interpretación. Claramente, esto plantea dudas sobre la legalidad del Sistema de Tribunales de Inversión, puesto que no garantiza una intervención preliminar y predominante del TJUE en la interpretación del DUE, de conformidad con el art. 19 TUE y tal como ha apuntado el TJUE en el Dictamen 2/2013, en relación al Tribunal Europeo de Derechos Humanos (paras. 236-248).

\section{La competencia exclusiva del TJUE respecto a la responsabilidad patrimonial de la $U E$}

A excepción del TJUE, los particulares no pueden generalmente reclamar daños y perjuicios ante instancias internacionales como consecuencia de un pretendido incumplimiento por parte del Estado del derecho internacional. Lejos de esta posición tradicional, los tratados de inversión establecen, en cambio, un régimen individualizado de responsabilidad estatal por daños y perjuicios causados en el ejercicio de potestades públicas que incluso es más amplio y está sujeto a menores restricciones que el articulado por el Tribunal de Justicia de la Unión Europea en el caso Francovich. 80

Respecto a la responsabilidad de la UE, a tenor de lo establecido en el Art. 268 TFUE, el TJUE ostenta la competencia exclusiva para conocer de los litigios relativos a la indemnización por los daños a los que se refiere el Artículo 340 del TFUE. Esto es, si un particular quiere demandar a la Unión Europea por daños y perjuicios, el TJUE es el único órgano jurisdiccional con competencia para resolver. Dicha competencia está fundada en el completo respeto al imperio de la ley y en el acceso no discriminatorio a la justicia y como tal no parece existir razón aparente, para excluir a los inversores, ya sea extranjeros o nacionales, de su ámbito de aplicación. ${ }^{81}$ Por otra parte, la remisión al arbitraje de inversiones en un tratado celebrado por la UE concede a los inversores extranjeros derechos especiales de ca-

80 Asuntos acumulados C-6/90 y C-9/90, Andrea Francovich y Danila Bonifaci y otros contra República Italiana, Sentencia del Tribunal de Justicia de 19 de noviembre de 1991, ECLI:EU:C:1991:428.

${ }^{81}$ Inge Govaere, op.cit., nota 9, p. 14. 
rácter procesal para dirimir la posible responsabilidad financiera de la UE resultante de la adopción de medidas contrarias al tratado de inversión correspondiente. Es frecuente, además, que estos tratados establezcan un sistema de fork in the road o «bifurcación de caminos», concediendo una alternativa procesal a los inversores extranjeros, que es excluyente de cualquier otra instancia jurisdiccional, tal como reflejan los art. 14.2 del Borrador TTIP y el art. 8.22.1 f) y g) del CETA.

Bajo la legislación de la UE las reclamaciones patrimoniales constituyen un recurso autónomo y limitado, ${ }^{82}$ excluyéndose recursos encubiertos de anulación u omisión y en las que a tenor de la jurisprudencia del TJUE es muy complicado, si no imposible, reclamar daños y perjuicios por actos lícitos ${ }^{83}$ En efecto, el TJUE ha intentado evitar cualquier riesgo de enfriamiento regulatorio consecuencia de una excesiva facilidad a la hora de admitir recursos por daños, sosteniendo que «la concepción restrictiva de la responsabilidad de la Comunidad en el ejercicio de su actividad normativa se explica por el hecho de que, por una parte, el ejercicio de la función legislativa, incluso cuando existe un control jurisdiccional de la legalidad de los actos, no debe verse obstaculizada por la perspectiva de reclamaciones de indemnización de daños y perjuicios cada vez que el interés general de la Comunidad exija adoptar medidas normativas que puedan lesionar los intereses de particulares y, por otra parte, por el hecho de que, en un contexto normativo caracterizado por la existencia de una amplia facultad de apreciación, indispensable para la aplicación de una política comunitaria, la Comunidad sólo incurre en responsabilidad si la institución de que se trata se ha extralimitado, de manera manifiesta y grave, en el ejercicio de sus facultades $[\ldots] \gg .{ }^{84}$

El enfoque del Tribunal de Justicia contrasta con el contexto del arbitraje de inversiones, donde son frecuentes las reclamaciones de daños y perjuicios con montantes bastante considerables como consecuencia de la adopción de medidas normativas internas, incluidas las adoptadas legalmente. El caso de la demanda iniciada por la compañía farmacéutica Elli Lilly contra Canadá ${ }^{85}$ tras la anulación de dos de sus patentes por tribunales federales canadienses y el la demanda interpuesta por Philip Mo-

82 Aranceli Mangas Martín y Diego Liñán Nogueras, Instituciones y Derecho de la UE,

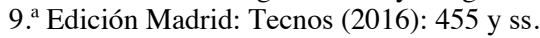

83 Asuntos acumulados C-120/06 P y C-121/06 P Fabbrica italiana accumulatori motocarri Montecchio SpA (FIAMM) y otros contra Consejo de la Unión Europea y Comisión de las Comunidades Europeas ECLI:EU:C:2008:476, paras. 164-169.

${ }^{84}$ Ibid, párrafo 174.

85 Eli Lilly and Company c. Canada (Caso CIADI Núm. UNCT/14/2), <www.icsid.worldbank.org/apps/icsidweb/cases/Pages/casedetail.aspx?caseno=UNCT/14/2 >. 
rris contra Australia ${ }^{86}$ con posterioridad a la adopción por ésta de la legislación sobre empaquetado genérico del tabaco a fin de proteger la salud pública son ilustrativos de este problema. ${ }^{87} \mathrm{~A}$ nivel europeo también destaca la demanda iniciada por la compañía sueca Vattenfall contra Alemania en relación con el Tratado de la Carta de Energía, en la que reclama entre 4 billones de euros y 6 billones de dólares como compensación por la decisión de Alemania de adoptar un opt-out nuclear después del desastre nuclear de Fukushima en marzo del $2011 .^{88}$ No es difícil anticipar el problema que puede suponer la admisión de reclamaciones por daños ante tribunales distintos al TJUE, menos recelosos de conceder indemnizaciones por la responsabilidad financiera resultante del ejercicio de una actividad normativa. Además de suponer una clara ventaja para los inversores extranjeros, podría originar una perversa presión competitiva a la hora de admitir recursos por daños ${ }^{89} \mathrm{Y}$ en este aspecto no habría diferencia entre el arbitraje de inversiones y Sistema de Tribunales de Inversión, a menos que este último alineara sus decisiones con la jurisprudencia del TJUE en aplicación del Art. 268 TFUE.

Pero incluso si el riesgo de enfriamiento regulatorio y la presión competitiva no resulten ser una amenaza real (de los dos casos significativos mencionados, Eli Lilly está pendiente de resolución y Philip Morris ha sido decidido a favor de Australia, condenándose a P. Morris al pago de las costas $^{90}$ ) la inserción de cláusulas arbitrales en tratados de inversión celebrados por la UE o la remisión al Sistema de Tribunales de Inversión plantean la cuestión más fundamental de una posible infracción de la jerarquía de normas en el Derecho europeo. A este respecto los acuerdos internacionales celebrados por la Unión Europea sólo tienen prioridad sobre la legislación derivada y las leyes de los Estados miembros en virtud del Artículo 216(2) del TFUE. Además, de conformidad con el Artículo 218(11) TFUE los acuerdos internacionales celebrados por la Unión Europea están sujetos al Dere-

86 Philip Morris Asia Limited (Hong Kong) c. The Commonwealth of Australia, La Haya, 16 mayo 2016, <www.pcacases.com/web/sendAttach/1713>.

87 Kyla Tienhaara, Chester Brown y Kate Miles, «Regulatory Chill and the Threat of Arbitration: A View from Political Science». Evolution in Investment Treaty Law and Arbitration, Cambridge: Cambridge University Press (2011), https://ssrn.com/ abstract $=2065706$.

88 Vattenfall AB y otros contra la República Federal Alemana (CIADI, Caso Núm. ARB/12/12), www.icsid.worldbank.org/apps/icsidweb/cases/Pages/casedetail. aspx ? caseno $=\mathrm{ARB} / 12 / 12 \& \operatorname{tab}=\mathrm{PRO}$.

89 Laurens Ankersmit, «Is ISDS in EU Trade Agreements Legal under EU Law?». www. iisd.org/itn/2016/02/29/isisdsineutradeagreementslegalundereulawlaurensankersmit.

${ }_{90}$ Laudo de 17 de diciembre de 2015, de la Corte Permanente de Arbitraje, www.pcacases.com/web/sendAttach/1711, Caso núm. 2012-12. 
cho originario de la Unión, por lo que han de ser necesariamente conformes con los Tratados Constitutivos y la Carta de los Derechos Fundamentales de la UE. En este contexto normativo, parece evidente que cualquier remisión en un tratado de inversiones celebrado por la UE a un tribunal distinto del TJUE entra en conflicto con la competencia exclusiva de éste para conocer los litigios por daños, conforme al Art. 268 TFUE. Obstáculo al que habría que añadir la ya mencionada estricta interpretación del TJUE respecto a la relación jurídica entre este y otros tribunales y órganos jurisdiccionales internacionales.

\section{La obligación de indemnizar monetariamente las infracciones a los derechos de los inversores}

Parece también oportuno analizar las posibles interferencias del arbitraje y del Sistema de Tribunales de Inversión en el funcionamiento del mercado interior. En particular, no podrían descartarse efectos indirectos como consecuencia de la obligación de indemnizar monetariamente las violaciones de los derechos sustantivos de los inversores. Un inversor extranjero, por ejemplo, podría impugnar ante el Tribunal de Inversiones una decisión de la Comisión por la que se le multa por abuso de posición dominante, sin que la Comisión haya probado un efecto perjudicial real para el mercado. La Comisión no fija las multas mediante criterios económicos y estas pueden llegar a constituir el 30\% de las ventas anuales de una empresa, pero un mayor escrutinio al respecto por el ICS podría impedir la efectividad de las competencias de ejecución de la Comisión y quizás distorsionar el buen funcionamiento del mercado interior. ${ }^{91}$ Bien es verdad que ante un laudo condenatorio el demandado solo estaría obligado en principio a indemnizar por daños y perjuicios y no a realizar una prestación específica que pusiera en liza el Derecho de la UE, tal como establece el art. 28.1 Borrador TTIP o el art. 8.39 CETA, lo que permitiría seguir aplicando en el contexto europeo normas de Derecho de la UE contrarios a un determinado tratado de inversiones, a cambio de pagar la indemnización correspondiente, situación similar a la que ocurre con el Derecho de la OMC. ${ }^{92}$ Pero hasta así podría darse el caso de que el pago de una indemnización monetaria fuera económicamente equivalente a una prestación específica, como por ejemplo, el reembolso de una subvención concedida infringiendo el Derecho de la UE. De he-

\footnotetext{
91 Laurens Ankersmit, op.cit., nota 89.

92 Stephan Schills, «Editorial: Opinion 2/13», op.cit., p. 385.
} 
cho, esa alegación fue aducida por Rumania y por la Comisión Europea, actuando como amicus curiae, en el caso Micula ${ }^{93}$ subrayando que un laudo arbitral que ordenara a Rumanía pagar una multa por retirar determinados incentivos en violación de las expectativas legítimas y la protección debida de los inversores bajo el Tratado Bilateral de Inversión Rumanía-Suecia iría contra la prohibición de ayudas estatales recogida en el art. 107 TFUE. Incluso con posterioridad a la emisión del laudo, en diciembre de 2013, ${ }^{94}$ cuando los inversores lograron que el Tribunal de Bucarest concediera la ejecución del laudo arbitral solicitada y ordenara el embargo de 36.484.232 de leus (unos 8,1 millones de euros) al Ministerio de Hacienda de Rumanía destinado al pago de las indemnizaciones y costas de ejecución, la Comisión requirió a Rumania que no ejecutara la decisión arbitral, ${ }^{95}$ hasta no emitir una Decisión final sobre la compatibilidad de la misma con el mercado interior. Entretanto, la Comisión incoó un procedimiento de infracción contra Rumanía que culminó en mayo de 2015 considerando dicho pago, junto con las deducciones de los impuestos adeudados por uno de los inversores demandantes a Rumanía, como ayuda estatal.$^{96}$ En opinión de la Comisión, mediante la ejecución del laudo arbitral se estaría concediendo a los inversores extranjeros una cantidad monetaria equivalente a las ventajas económicas previstas en virtud del programa derogado previo a la adhesión de Rumanía a la Unión Europea. Tales ventajas, de las que no dispondrían en condiciones normales de mercado, constituirían una concesión indirecta de ayuda estatal considerada ilegal e incompatible con el mercado interior. ${ }^{97}$ Para la Comisión Europea resultaba irrelevante que la obligación de Rumanía de abonar esas cantidades resultase de un tratado internacional, ya que un tratado concluido entre dos Estados miembros de la Unión Europea no

93 Ioan Micula, Viorel Micula, S.c. European Food s.a, s.c. Starmill S.R.L. y S.C. Multipack S.R.L. c. Rumania, Caso CIADI No. ARB/05/20, Laudo Final, 11 diciembre 2013.

${ }^{94}$ Ioan Micula, Viorel Micula, S.C. European Food S.A, S.C. Starmill S.R.L. and S.C. Multipack S.R.L. v. Romania, ICSID Case No. ARB/05/20. <http://www.italaw.com/ cases/697 > último acceso 5 de febrero de 2017.

95 Decisión C (2014) 3192 final de la Comisión, de 26 de mayo de 2014, en el asunto sobre ayudas de Estado SA.38517 (2014/NN) - Micula v Rumanía (laudo arbitral del CIADI), por la que se ordena a Rumanía la suspensión de cualquier actuación con vistas a la ejecución o a la aplicación del laudo arbitral de 11 de diciembre de 2013.

96 Decisión (UE) 2015/1470 de la Comisión, de 30 de marzo de 2015, relativa a la ayuda estatal SA. 38517 (2014/C) (ex 2014/NN) ejecutada por Rumanía Laudo arbitral Micula/Rumanía de 11 de diciembre de 2013.

${ }^{97}$ En consonancia con lo decidido en el Asunto T-384/08, Elliniki Nafpigokataskevastiki AE Chartofylakeiou/Comisión, EU:T:2011:650, y Asunto T-565/08, Corsica Ferries/Comisión, EU:T:2012:415, apartados 23, 114 y 120 a 131. Véase también, por analogía, el asunto C-111/10, Comisión/Consejo, EU:C:2013:785, apartado 44. 
puede aplicarse cuando con ello se impida la aplicación del Derecho de la Unión en materia de ayudas de Estado. ${ }^{98}$

La Decisión de la Comisión está recurrida ante el Tribunal General mediante un recurso de anulación interpuesto por algunos de los inversores afectados, pero en cualquier caso, aunque el fallo sea favorable a la Comisión Europea, sus efectos tendrían un carácter limitado. En primer lugar, los laudos arbitrales condenatorios al pago de una cantidad monetaria pueden ser susceptibles de ejecución fuera del territorio de la Unión Europea, por tribunales que no están obligados a respetar el Derecho de la Unión en materia de ayudas de Estado. Así por ejemplo, cuando el demandante quiso ejecutar el laudo en los Estados Unidos, Rumania alegó que no podía pagar por los daños y perjuicios porque la Comisión le prohibía hacerlo, argumento que fue, sin embargo, rechazado por un tribunal del Estado de Nueva York señalando que los laudos CIADI no pueden ser revisados en cuanto al fondo. ${ }^{99} \mathrm{Y}$ en segundo lugar, aunque se falle a favor de la Comisión Europea, la obligación impuesta a un Estado miembro de suprimir una ayuda considerada incompatible con el mercado interior está diseñada para restablecer la situación previamente existente, objetivo que se consigue cuando el receptor reembolsa los importes concedidos en concepto de ayuda ilegal, perdiendo así la ventaja de la que había disfrutado sobre sus competidores en el mercado y se restablece la situación anterior. Pero es que, en este sentido, ejecutar la orden de la Comisión sería impracticable, ya que no existe ningún mecanismo para recuperar importes efectivamente pagados por Rumanía de conformidad con el Derecho internacional.

Las conclusiones no son diferentes si extrapolamos el panorama anterior al contexto de los tratados de inversión celebrados directamente por la UE en ejercicio de su competencia exclusiva. En efecto, el reconocimiento del pago de indemnizaciones monetarias como remedio exclusivo frente a las violaciones de los derechos sustantivos de los inversores recogido en los nuevos tratados negociados y celebrados por la UE tales como reflejan el Art. 28.1 Borrador TTIP o el Art 8.39 CETA, no parece poder evitar posibles injerencias de las decisiones arbitrales en el funcionamiento del mercado interior. La única diferencia respecto al caso Micula es que en este caso, cualquier posible incompatibilidad con el Derecho de la Unión estaría siendo rubricada por la Unión Europea como actor principal.

98 Decisión (UE) 2015/1470 de la Comisión, supra, párrafo104.

99 « $[\mathrm{t}] \mathrm{o}$ do otherwise would undermine the ICSID Convention's expansive spirit on which many American investors rely when they seek to confirm awards in the national courts of the Convention's other member states.» Micula v. Romania, United States District Court, Southern District of New York, No. 15 Misc. 107, Decisión de 5 agosto de 2015. 


\section{Exclusión del efecto directo y discriminación por razón de nacionalidad}

Además de considerar el derecho interno como una cuestión meramente fáctica, se ha excluido de forma expresa, al menos en el caso del Acuerdo con Canadá (art. 30.6), el efecto directo sus normas al objeto de evitar su integración en el Derecho de la Unión Europea. ${ }^{100}$ En realidad ello no es más que la confirmación oficial de la práctica habitual respecto a la negación del efecto directo en los acuerdos internacionales celebrados por la UE. ${ }^{101}$ Aunque el efecto directo no ha sido totalmente descartado, el TJUE ha reiterado en este sentido que, en principio, el derecho del GATT o de la OMC no se pueden invocar en la revisión la legalidad de los actos internos, porque son demasiado flexibles e imprecisos. ${ }^{102}$ Así pues, ni los tribunales nacionales ni el TJUE podrían aplicar las normas CETA en procedimientos internos ni los particulares invocarlas, excluyéndose cualquier impacto en el Derecho de la UE por esa vía. Es de esperar que el TTIP incluya un precepto parecido, ${ }^{103}$ de manera que tanto CETA como TTIP recibirían el mismo tratamiento que el otorgado por el TJUE al Derecho de la OMC, que tampoco tiene efecto directo, ni siquiera en situaciones en las que el órgano de apelación confirma que la legislación interna es incompatible con las normas de la OMC. ${ }^{104}$

100 Artículo 30.6 CETA: Derechos privados: 1. Ninguna disposición del presente Acuerdo se interpretará en el sentido de que conceda derechos o imponga obligaciones a personas, distintos de los creados entre las Partes en virtud del Derecho internacional público, ni en el sentido de que el presente Acuerdo pueda invocarse directamente en los ordenamientos jurídicos internos de las Partes. 2. Ninguna de las Partes podrá prever un derecho de recurso con arreglo a su Derecho interno contra la otra Parte aduciendo que una medida de la otra Parte es incompatible con el presente Acuerdo.

101 Gerhard Bebr, «Agreements Concluded by the Community and their Possible Direct Effect: From International Fruit Company to Kupferberg», Common Market Law Review, 20 (1983): 35-73. Asuntos acumulados 21-24/72, International Fruit Company NV $y$ otros c. Produktschap voor Groenten en Fruit, Sentencia del Tribunal de Justicia de 12 de diciembre de 1972, ECLI:EU:C:1972:115; Asunto C-280/93, Alemania c. Consejo, Sentencia del Tribunal de Justicia de 5 de octubre de 1994, ECLI:EU:C:1994:367; Asunto C-149/96, República Portuguesa contra Consejo de la Unión Europea, Sentencia del Tribunal de Justicia de 23 de noviembre de 1999, ECLI:EU:C:1999:574. Críticamente, GRILLER, S. «Judicial Enforceability of WTO Law in the European Union, Annotation to Case C-149/96, Portugal v Council,» Journal of International Economic Law, Vol. 3/ 3 (2000):441-472.

102 C-149/96. Asunto C-149/96, República Portuguesa contra Consejo de la Unión Europea, op.cit.

103 Legal Implications of the TTIP for the Acquis Communautaire in ENVI Relevant Sectors, IP/A/ENVI/ST/2013-09, Directorate General for Internal Policies, p. 13.

104 Pieter Jan Kuijper and Marco Bronckers, «WTO Law in the European Court of Justice». Common Market Law Review, 42 (2005): 1313-1355. 
La falta de reciprocidad se menciona generalmente como el argumento que justifica la exclusión del efecto directo en el CETA o TTIP, puesto que ni el Derecho de los Estados Unidos ni el de Canadá permiten a los tribunales el conocimiento de demandas de particulares directamente basadas en acuerdos comerciales. ${ }^{105}$ Como argumento contrario se aduce que aunque no haya reciprocidad con los Estados Unidos y Canadá respecto al TTIP y CETA, cada Estado miembro tiene la libertad constitucional básica de elegir el sistema mediante el que prefiere de dar efecto al derecho internacional público, tal como dictaminó el Tribunal de Justicia en Kupferberg. ${ }^{106}$ Así, la falta de reciprocidad en dichos Estados no constituye un problema insalvable para reconocer el efecto directo de los acuerdos comerciales que concluya la UE. ${ }^{107}$ En este sentido se subraya que la posibilidad de invocar disposiciones del CETA o TTIP en procedimientos judiciales internos no solo atendería a los intereses estadounidenses o canadienses, sino también a los de los ciudadanos de la UE, cuyos tribunales nacionales podrían controlar la actividad interna de la UE a la luz de los principios de buen gobierno del TTIP, CETA y otros acuerdos similares. ${ }^{108}$

Cualquiera que sea la razón última que ha impulsado a la exclusión del efecto directo en el CETA y TTIP no deja de sorprender que la Unión Europea haya reforzado la existencia de este mecanismo paralelo y externo de resolución de controversias pues precisamente los Servicios Jurídicos de la Comisión criticaron en Euram c. Eslovaquia que «El tribunal arbitral no es una corte o un tribunal de un Estado miembro, sino un mecanismo de solución de controversias paralelo totalmente externo el marco institucional y judicial de la Unión Europea. Tal mecanismo priva a los tribunales de los Estados miembros de sus competencias en relación con la interpretación y aplicación de las normas de la UE que imponen obligaciones a los Estados

105 Oona Hathaway et al., «International Law at Home: Enforcing Treaties in U.S. Courts». Yale Journal of International Law, 37 (2012): 51-106. Tal como declaró el portavoz de la Comisión Europea, John Clancy, el 20 diciembre de 2013 respecto a la introducción de mecanismos de ISDS en el TTIP:

«The reason ISDS is needed in TTIP is that the US system does not allow companies to use international agreements like TTIP as a legal basis in national courts. So European companies - and especially SMEs - will only be able to enforce the agreement through an international arbitration system like ISDS», 20 diciembre 2013, DG Comercio, News archive, www.trade.ec.europa.eu/doclib/press/index.cfm?id=1008.

106 Asunto C-104/81, Hauptzollamt Mainz v C.A. Kupferberg \& Cie KG a.A., Sentencia del Tribunal de Justicia de 26 de octubre de 1982, ECLI:EU:C:1982:362.

107 Marco Bronckers, «Is Investor-State Dispute Settlement (ISDS) superior to litigation before domestic courts?». Journal of International Economic Law, 18/ 3 (2015): 655-677, 666.

108 Ibid. 
miembros». ${ }^{109}$ Paradójicamente, al excluir el efecto directo del TTIP, CETA o de otros Acuerdos que celebre, la UE estaría reforzando el tratamiento especial y externo que se le otorga a los inversores extranjeros en el ISDS y que tanto está siendo criticado por sectores de la opinión pública europea. Así, asociaciones como el Deutscher Richterbund, ${ }^{110}$ la Asociación de Jueces Alemanes, o la Asociación de Jueces para la Democracia en España ${ }^{111}$ claman que es inadmisible que la protección jurídica a los inversores sea resuelta por un tribunal arbitral al margen del organigrama judicial estatal y europeo, lo que supone una usurpación de las funciones judiciales estatales, caracterizadas por su independencia e imparcialidad, para adjudicarlas a un organismo vinculado a las grandes corporaciones económicas y a los gobiernos más importantes del mundo.

De ser así, el pretendido Tribunal de Inversiones no solo arrojaría dudas sobre su compatibilidad con el organigrama judicial estatal y europeo sino que podría chocar de frente con el principio de no discriminación por razón de nacionalidad. Ciertamente, el Tribunal de Inversiones, tal como propone la Comisión, daría a los inversores extranjeros derechos especiales de protección judicial de los que carecen de los inversores nacionales, reforzado por el hecho de que a los primeros se les permitiría acudir a dicho Tribunal sin antes de recurrir a los recursos judiciales internos. ${ }^{12}$ Según el art. 218.11 TFUE los acuerdos internacionales celebrados por la Unión Europea deben cumplir con el Derecho originario de la Unión, incluida la Carta de los Derechos Fundamentales de la UE. En este sentido, si un acto de la UE afecta por igual a un inversor extranjero y a un inversor europeo, permitir solo al primero activar un sistema de judicial paralelo y externo al organigrama judicial estatal y europeo no parece encajar bien en el art. 20 de la Carta de Derechos Fundamentales de la UE que prescribe que «todo

109 Escrito de amicus curiae de la Comisión Europea en European American Investment Bank AG (EURAM) c. Slovak Republic (13 octubre 2011) SJ.i.dir (2011) 1154556.

110 Stellungnahme zur Errichtung eines Investitionsgerichts für TTIP - Vorschlag der Europäischen Kommission vom 16.09.2015 und 12.11.2015 http://www.drb.de/fileadmin/ docs/Stellungnahmen/2016/DRB_160201_Stn_Nr_04_Europaeisches_Investitionsgericht.pdf (acceso 29 junio de 2016).

111 «pD sobre el TTIP y la creación de un tribunal especial», Jueces para la democracia. http://juecesparalademocracia.blogspot.com.es/2016/05/jpd-sobre-el-ttip-y-la-creacion-de-un. html, a 11 de mayo de 2017.

112 Respecto al arbitraje de inversiones, el caso de los recortes a las energías renovables en España constituye un claro ejemplo. Miles de inversores nacionales han visto cómo sus demandas han sido sistemáticamente rechazadas por los tribunales nacionales mientras que los inversores extranjeros han interpuesto demandas millonarias, con visos de prosperar, ante tribunales arbitrales de inversión. Vid., Ana M. López-Rodríguez y Pilar Navarro, «Investment Arbitration and EU Law in the Aftermath of Renewable Energy Cuts in Spain», European Energy and Environmental Law Review, Vol. 25, 2016, pp. 2-10. 
el mundo es igual ante la ley» o en el art. 21, también de la Carta, que contiene una clara prohibición de la discriminación basada en la nacionalidad. ${ }^{113}$

En 2014 la Comisión Europea solicitó un Dictamen consultivo al TJUE respecto a la competencia para firmar y ratificar el Tratado de Libre Comercio con Singapur. ${ }^{114}$ Queda por ver si el TJUE aprovechará esta oportunidad para dar su opinión sobre la compatibilidad de los mecanismos tradicionales de resolución de controversias inversor-Estado con el DUE. Quizás tendremos que esperar a la solicitud de un dictamen independiente en relación al TTIP y CETA, como el que se prevé en la «Declaración del Reino de Bélgica relativa a las condiciones aplicables a los plenos poderes del Estado Federal y las Entidades Federadas para la firma del AECG». ${ }^{115}$ Atendiendo a la misma Bélgica solicitará al Tribunal de Justicia de la Unión Europea que se pronuncie sobre la compatibilidad del Sistema de Tribunales de Inversión con el Derecho de la UE, de conformidad con el artículo 218, apartado 11, del TFUE, esencial para que el Gobierno valón abandone su veto contra CETA. Pero a la luz de lo analizado en las líneas que preceden podemos anticipar que existen poderosos obstáculos que cuestionan la legalidad del Sistema de Tribunales de Inversión y no hay ninguna razón para creer que el TJUE, de ser consultado al respecto, vaya a ser más condescendiente con el mencionado Tribunal que con el Tribunal Europeo de Derechos Humanos en su Dictamen 2/2013.

\section{Conclusiones}

El objetivo principal del presente trabajo ha sido analizar el modelo de Sistema de Tribunales de Inversión propuesto por la Comisión Europea a la luz del Derecho europeo. Entre los varios obstáculos que se han analizado y que habría que sortear destaca la necesidad de garantizar los

$113 \mathrm{Si}$ bien es verdad que al abordar algunos aspectos de la llamada «discriminación inversa», es decir, cuando un Estado miembro trata a sus propios ciudadanos menos favorablemente que a cualquier otro ciudadano de la Unión, el TJUE ha reiterado que es una consecuencia inevitable y normal de la división de competencias entre la Unión y sus Estados miembros según lo establecido por los tratados. Vid. Hanf, Dominik, «Reverse Discrimination in EU Law: Constitutional Aberration, Constitutional Necessity, or Judicial Choice?» Maastricht Journal of European and Comparative law, Vol. 18, 2011, pp. 29-61.

114 Dictamen 2/2015, http://curia.europa.eu/juris/document/document.jsf?text=\&docid=1 70868 \&pageIndex $=0 \&$ doclang $=E S \&$ mode $=1$ st $\&$ dir $=\& o c c=$ first $\&$ part $=1 \&$ cid $=387569$.

115 L. Doue, 11, 14 enero 2017, http://eur-lex.europa.eu/legalcontent/ES/TXT/PDF/?uri= CELEX:22017X0114(02)\&from=ES. 
principios de autonomía y primacía, asegurando que ningún otro órgano jurisdiccional pueda vincular a la Unión Europea y a sus instituciones mediante una determinada interpretación del Derecho de la UE. La respuesta de la Comisión Europea ha sido la exclusión de la competencia del Tribunal de Inversiones para determinar la legalidad de una medida bajo el derecho interno y la consideración de este como mera cuestión incidental y fáctica. No obstante, como se ha argumentado en este trabajo, no está claro que el tratamiento del derecho interno como cuestión fáctica vaya a cambiar el proceso de razonamiento del Tribunal en cuestión, persistiendo el riesgo de interpretaciones paralelas del DUE, que en caso de reiteración, podrían llegar a convertirse en una suerte de precedente de facto. Las circunstancias mencionadas se agravan porque aunque el Tribunal de Inversiones habría de seguir la interpretación predominante del derecho interno establecida por los tribunales o autoridades de las parte firmantes del Acuerdo, dicho Tribunal no estaría directamente obligado a solicitar ni tendría competencia para someter al TJUE una cuestión prejudicial de interpretación. Con ello surgen dudas sobre la legalidad de la propuesta, puesto que no garantiza una intervención preliminar y predominante del TJUE en la interpretación del DUE, de conformidad con el art. 19 TUE y en línea con la doctrina del TJUE en relación al Tribunal Europeo de Derechos Humanos (Dictamen 2/2013, paras. 236-248).

Además, la creación de un Sistema de Tribunales de Inversión para el arreglo de controversias por la infracción de las normas de protección de los inversores puede cuestionar la competencia exclusiva del TJUE establecida en el artículo 268 TFUE para conocer de los litigios relativos a la indemnización por los daños ex artículo 340 del TFUE. No es difícil anticipar el problema que podría suponer la admisión de reclamaciones por daños ante tribunales distintos al TJUE, más dispuestos a conceder indemnizaciones por la responsabilidad financiera resultante del ejercicio de una actividad normativa. Y en este aspecto no habría diferencia entre el arbitraje de inversiones y el Sistema de Tribunales de Inversión propuesto por la Comisión, a menos que este último alineara sus decisiones con la jurisprudencia del TJUE en aplicación del Art. 268 TFUE.

De igual forma se presentan tensiones entre el arbitraje y el Sistema de Tribunales de Inversión, por una parte y la competencia reguladora de la Unión Europea respecto al funcionamiento del mercado interior, por otro. Entre otras cuestiones, la consolidación del pago de indemnizaciones monetarias como remedio exclusivo frente a las violaciones de los derechos sustantivos de los inversores, como reflejan los arts. 28.1 Borrador TTIP y 8.39 CETA, no parece poder paliar esas posibles injerencias, por resultar en algunas ocasiones equivalentes a una prestación específica. 
Por último, el nuevo modelo introducido por la Comisión excluye también de forma expresa el efecto directo de las normas del CETA y, posiblemente, del TTIP, por lo que ni los tribunales nacionales ni el TJUE podrán aplicar sus normas en procedimientos internos ni los particulares invocarlas, excluyéndose cualquier impacto del derecho de inversiones en el Derecho de la UE por esa vía. Pero este planteamiento de la Comisión no hace sino reforzar el tratamiento especial y externo que se le otorga a los inversores extranjeros que tanto está siendo criticado por sectores de la opinión pública europea y la doctrina y que puede incluso ser contrario a los arts. 20 y 21 de la Carta de Derechos Fundamentales de la UE por discriminatorio.

La Comisión Europea, originariamente partidaria de la inclusión de mecanismos de ISDS en los acuerdos comerciales post-Lisboa, ha dado un giro a su posición inicial y ahora propone un Sistema de Tribunales de Inversión, para salir al paso de las críticas en algunos sectores de la opinión pública europea. Es cierto que el Sistema de Tribunales de Inversión introduce importantes ventajas en términos de transparencia, independencia y consistencia de soluciones por su carácter permanente y la introducción de un recurso de apelación. Pero sigue sin justificar el porqué del trato privilegiado a inversores extranjeros sobre otros inversores nacionales o los ciudadanos en general. En realidad la cuestión de fondo es la conveniencia o no de mantener mecanismos especiales para la resolución de controversias inversor-Estado. Para un sector importante de la sociedad civil es inadmisible que la protección jurídica a los inversores sea resuelta por un Tribunal al margen del organigrama judicial estatal y europeo, lo que supone una usurpación de las funciones judiciales estatales, caracterizadas por su independencia e imparcialidad, para adjudicarlas a un organismo vinculado a las grandes corporaciones económicas y a los gobiernos más importantes del mundo. En opinión de algunos, además, no es lógico remitir a un Tribunal especial en los Acuerdos entre la UE y EEUU o Canadá, por tratarse de países que tienen un sistema judicial perfectamente capacitado para dirimir controversias con inversores extranjeros sobre la base de la legislación aplicable al resto de la sociedad. A favor del Sistema de Tribunales de Inversión se puede argumentar, sin embargo, que la exclusión de mecanismos de arreglo de diferencias inversor-Estado puede ser perfectamente entendible - que no necesariamente plausible - en las relaciones con los Estados Unidos y Canadá, pero abandonar los mecanismos de resolución de controversias de inversión y remitir a órganos judiciales estatales quizás no sea del todo pertinente en Acuerdos con China, Rusia u otros Estados más alejados de nuestras tradiciones jurídicas. Y esta circunstancia ha de ser tenida en cuenta si la idea es que tanto el CETA como el TTIP se conviertan en el 
gold standard, es decir, en el modelo a seguir por la UE en los acuerdos comerciales que celebre en el futuro.

En cualquier caso, lo que sí está meridianamente claro es que el modelo propuesto por la Comisión Europea necesita ser revisado. No se ha prestado mucha atención a cuestiones jurídicas de base que pueden constituir verdaderos escollos desde el punto de vista del DUE. Cuestiones de legalidad, que por otra parte, también se plantean en relación al arbitraje de inversiones. También se ha de superar la tensa relación entre el TJUE y otros tribunales internacionales, asunto que parece de difícil solución ya que aunque el TJUE no rechaza a priori la existencia de los mismos, su doctrina demuestra una posición extremadamente defensiva.

El primer Dictamen consultivo sobre a la competencia de la UE para firmar y ratificar el Tratado de Libre Comercio con Singapur está a punto de ser publicado. Queda por ver si el TJUE aprovechará esta oportunidad para dar su opinión sobre la compatibilidad de los mecanismos tradicionales de resolución de controversias inversor-Estado con el DUE, pero con respecto al Sistema de Tribunales de Inversión seguramente tendremos que esperar a la solicitud de un Dictamen independiente, como el que se prevé en la Declaración del Reino de Bélgica relativa a las condiciones aplicables para la firma del CETA.

Una vez que se fijen las condiciones de compatibilidad, se deberán sortear los posibles obstáculos marcando una línea clara a seguir en el arreglo de controversias inversor-Estado. La remisión a los tribunales nacionales no parece ser una solución apropiada, sobre todo a nivel mundial, pero la existencia de tribunales externos, como el Sistema de Tribunales de Inversión, solo abierto a inversores extranjeros y donde no se les puede exigir responsabilidad por infracciones a la normativa medioambiental, laboral etc. tampoco parece convencer a los sectores críticos de la doctrina y de la opinión pública. ${ }^{116}$ Representantes de la Comisión Europea han llegado a afirmar que el ISDS está muerto («ISDS is dead»), ${ }^{117}$ pero la solución que propone la Comisión debilita la credibilidad general del arbitraje de inversiones como mecanismo legítimo de resolución de controversias, al mismo tiempo que se aferra a muchas de sus característi-

116 Gus Van Harten, «Key flaws in the European Commission's proposals for foreign investor protection in TTIP». Osgoode Legal Studies Research Paper 16, 12/4 (2016), http:// ssrn.com/abstract=2692122. N. Cingotti (ed.), Investment Court System: ISDS in Disguise, Friends of the Earth Europe, www.foeeurope.org/sites/default/files/eu-us_trade_deal/2016/ investment_court_system_isds_in_disguise_10_reasons_why_the_eus_proposal_doesnt_ fixed_a_flawed_system_english_version_0.pdf.

${ }_{117}$ Daniela Vicenti, «Pittella: ISDS is dead, EU-Canada trade deal must be reopened». EurActiv.com, 3 julio (2015). 
cas como, por ejemplo, haciendo referencia al Reglamento de Arbitraje de la CNUDMI o a la Convención CIADI. ${ }^{118} \mathrm{Si}$ el objetivo es crear un verdadero Tribunal de Inversiones, se deberá soltar el lastre del arbitraje. Y sobre todo, si la idea es mantener un sistema externo y paralelo para el arreglo de controversias inversor-Estado, la Unión Europea habrá de hacer más esfuerzos explicativos.

\section{Bibliografía}

Bronckers, Marco. «Is Investor-State Dispute Settlement (ISDS) superior to litigation before domestic courts?». Journal of International Economic Law, 18/ 3 (2015): 655-677, 666.

Cantero Martínez, Josefa. «Arbitraje internacional de inversiones y «derecho a regular» de los estados: el nuevo enfoque comunitario en la negociación del TTIP». Revista Española de Derecho Europeo, 58 (2016): 13-45. Croft ET AL., A Guide to the UNCITRAL Arbitration Rules. Cambridge: Cambridge University Press, 2013.

Cross, Ciaran y Christian Schliemann-Radbruch, C. «When Investment Arbitration Curbs Domestic Regulatory Space: Consistent Solutions through Amicus Curiae Submissions by Regional Organisations». Law and Development Review, 6/2 (2013): 67-110.

Fach Gómez, Katia. «Unión Europea e inversiones internacionales: el futuro de los mecanismos de resolución de controversias inversor-Estado». Revista Española de Derecho Internacional, 69/1 (2017): 295-302.

Fernádez Masiá, Enrique. «iEs compatible la confidencialidad con el arbitraje en inversiones extranjeras?: Hacia una mayor transparencia y participación de terceros en los procedimientos arbitrales inversor-Estado». Revista vasca de derecho procesal y arbitraje $=$ Zuzenbide prozesala ta arbitraia euskal aldizkaria, 19/1 (2007): 1-14.

Fernádez, Enrique. «Atribución de competencia a través de la cláusula de nación más favorecida: lecciones extraídas de la reciente práctica arbitral en materia de inversiones extranjeras». Revista electrónica de estudios internacionales (REEI), 13 (2007)

Fernández, Enrique. «Arbitraje Inversor-Estado: De "Bella Durmiente" A "León En La Jungla"». Revista electrónica de estudios internacionales (REEI), 26 (2013).

Fernández Rozas, José Carlos. «Internacionalismo vs Mercatorismo en la Especialización del Arbitraje Internacional», Arbitraje, Revista de Arbitraje Comercial y de Inversiones, 5/ 1 (2012): 37-90, 70.

118 Katia Fach Gómez, «Unión Europea e inversiones internacionales: el futuro de los mecanismos de resolución de controversias inversor-Estado». Revista Española de Derecho Internacional, 69/1 (2017): 295-302. 
Fernández Rozas, José Carlos. «La compleja adhesión de la Unión Europea al Convenio Europeo de Derechos Humanos y las secuelas del Dictamen 2/2013 del Tribunal de Justicia». La Ley Unión Europea, 23 (2014): 40-56.

Foster, Caroline. «A New Stratosphere? Investment Treaty Arbitration as Internationalized Public Law». International and Comparative Law Quarterly, 64 (2015): 461-485.

Franck, Susan. «The Legitimacy Crisis in Investment Treaty Arbitration: Privatizing Public International Law through Inconsistent Decisions». Fordham Law Review, 73 (2005): 1521-1625.

Fry, James. «Towards a New World for Investor-State Arbitration through Transparency». New York University Journal of International Law and Politics, 48 (2016): 796-865.

Govaere, Inge. TTIP and Dispute Settlement: Potential Consequences for the Autonomous EU Legal Order, Research Papers in Law, 1/2016, Department of Legal Studies, College of Europe.

Hinojosa Martínez, Luis Miguel. «El alcance de la competencia exterior europea en materia de inversiones». Revista de Derecho Comunitario Europeo, 52 (2015): 871-907.

Iruretagoiena Agirrezabalaga, Iñigo. «Competencia de la Unión Europea en materia de inversiones extranjeras y sus implicaciones en el arbitraje inversorEstado». Arbitraje, Revista de arbitraje comercial y de inversiones, 4/1 (2011): 117-136.

Iruretagoiena Agirrezabalaga, Iñigo. «Contract claims y treaty claims: relación entre las cláusulas umbrella y los acuerdos contractuales de atribución de competencia exclusiva». Arbitraje, Revista de Arbitraje Comercial y de Inversiones, 3/3 (2010): 797-811.

Iruretagoiena Agirrezabalaga, Iñigo. «La firma del Acuerdo Económico y Comercial Global entre la Unión Europea y Canadá: un primer y decisivo paso hacia el establecimiento de un renovado marco legal para las inversiones extranjeras en el ámbito europeo y global». La Ley Unión Europea, 42 (2016).

Jančić, Davor. «The Role of the European Parliament and the US Congress in Shaping Transatlantic Relations: TTIP, NSA Surveillance, and CIA Renditions». Journal of Common Market Studies, Vol. 54, 4 (2016): 896-912, 902.

Kläger, Roland. Fair and Equitable Treatment in International Investment Law, Cambridge: Cambridge University Press (2011): 21.

Kleinheisterkamp, Jan. «Financial Responsibility in European International Investment Policy». International and Comparative Law Quarterly, 63 (2014): 449-476.

Kuijper, Pieter Jan and Bronckers, Marco. «WTO Law in the European Court of Justice». Common Market Law Review, 42 (2005): 1313-1355.

Mangas Martín, Aranceli y Liñán Nogueras, Diego. Instituciones y Derecho de la $U E$, 9. . Edición Madrid: Tecnos (2016): 455 y ss.

Pascual Vives, Francisco José. «El Subsistema Regional Comunitario ante el Régimen Internacional de Protección de las Inversiones Extranjeras». Revista de Derecho Comunitario Europeo, 36 (2010): 467-495. 
Schill, Stephan. «Editorial: Opinion 2/13 - The End for Dispute Settlement in EU Trade and Investment Agreements?». The Journal of World Investment \& Trade, 16 (2005): 379-388.

Schill, Stephan. «The Mauritius Convention on Transparency». The Journal of World Investment \& Trade, 16/2 (2015): 201-204.

Schill, Stephan. «Crafting the International Economic Order: The Public Function of Investment Treaty Arbitration and Its Significance for the Role of the Arbitrator». Leiden Journal of International Law, 23 (2010): 401-430, 412.

Strik, Philip. «Shaping the Single European Market in the Field of Foreign Direct Investment». Oxford and Portland, Oregon: Hart Publishing (2014): 240 ss.

Tienhaara, Kyla, Brown, Chester y Miles, Kate. «Regulatory Chill and the Threat of Arbitration: A View from Political Science». Evolution in Investment Treaty Law and Arbitration, Cambridge: Cambridge University Press (2011).

Van Harten, Gus y Martin Loughlin, «Investment Treaty Arbitration as a Species of Global Administrative Law». The European Journal of International Law, 17/1 (2006): 121-150.

Van Harten, Gus «A Case for an International Investment Court». Society for International Economic Law, Online Proceedings, Working Paper, 22/08.

Van Harten, Gus «Key flaws in the European Commission's proposals for foreign investor protection in TTIP». Osgoode Legal Studies Research Paper 16, 12/4 (2016).

\section{Sobre el autor}

Ana Mercedes López Rodríguez es Profesora Titular de Derecho Internacional Privado en la Universidad Loyola Andalucía (España) y pertenece al Cuerpo Superior de Administradores Generales de la Junta de Andalucía (en excedencia). Ha participado en Proyectos europeos y nacionales, centrando sus investigaciones en los campos del Derecho Internacional Privado Europeo, el Derecho de la Unión Europea y Arbitraje Comercial Internacional y de Inversiones. Entre sus principales publicaciones en temática europea, destacan: Lex Mercatoria and Harmonization of Contract Law in the EU, DJØF Publishing, Copenhague, 2003 (ISBN 87-5740947-1); «Towards a European Civil Code without a Common European Legal Culture? - the Link between Law, Language and Culture», 29 Brooklyn Journal of International Law, n. 3, 2004, pp. 1195-1220; «EU-rettens påvirkning af formueretten - det formelle og det faktiske perspektiv», Ugeskrift for Retsvaesen, Vol. 14, n. ${ }^{\circ} 3,2004$, pp. 115-121; «El contrato de distribución exclusiva o concesión comercial como contrato de prestación de servicios a efectos de la aplicación del foro contractual del Reglamento de Bruselas I», La Ley Unión Europea, vol. 13, 2014, pp. 37-44; «Los pac- 
tos de exclusiva en los contratos de abanderamiento y suministro a estaciones de servicio y el Derecho europeo de la competencia», La Ley Unión Europea, vol. 24, 2015, pp. 62-71; «Investment Arbitration and EU Law in the Aftermath of Renewable Energy Cuts in Spain», European Energy and Environmental Law Review, Vol. 25, 2016, pp. 1-10 (junto a Pilar Navarro Rodríguez).

\section{About the author}

Ana Mercedes López Rodríguez is Associate Professor of Private International Law at the University Loyola Andalusia (Spain). Member of the Higher Corps of Civil Administrators of the autonomous region of Andalusia (on leave). She has participated in different European and Spanish research projects. Her main lines of research are Private International Law of the European Union, European Union Law and Commercial and Investment Arbitration. Selected publications in the field of European Law: Lex Mercatoria and Harmonization of Contract Law in the EU, DJØF Publishing, Copenhaguen, 2003 (ISBN 87-574-0947-1); «Towards a European Civil Code without a Common European Legal Culture? - the Link between Law, Language and Culture», 29 Brooklyn Journal of International Law, n. 3, 2004, pp. 1195-1220; «EU-rettens påvirkning af formueretten - det formelle og det faktiske perspektiv», Ugeskrift for Retsvasen, Vol. 14, n. . 3, 2004, pp. 115-121; «El contrato de distribución exclusiva o concesión comercial como contrato de prestación de servicios a efectos de la aplicación del foro contractual del Reglamento de Bruselas I», La Ley Unión Europea, vol. 13, 2014, pp. 37-44; «Los pactos de exclusiva en los contratos de abanderamiento y suministro a estaciones de servicio y el Derecho europeo de la competencia», La Ley Unión Europea, vol. 24, 2015, pp. 62-71; «Investment Arbitration and EU Law in the Aftermath of Renewable Energy Cuts in Spain», European Energy and Environmental Law Review, Vol. 25, 2016, pp. 1-10 (co-written with Pilar Navarro Rodríguez). 


\section{Derechos de autor}

Los derechos de autor (para la distribución, comunicación pública, reproducción e inclusión en bases de datos de indexación y repositorios institucionales) de esta publicación (Cuadernos Europeos de Deusto, CED) pertenecen a la editorial Universidad de Deusto. El acceso al contenido digital de cualquier número de Cuadernos Europeos de Deusto es gratuito inmediatamente después de su publicación. Los trabajos podrán leerse, descargarse, copiar y difundir en cualquier medio sin fines comerciales y según lo previsto por la ley; sin la previa autorización de la Editorial (Universidad de Deusto) o el autor. Así mismo, los trabajos editados en CED pueden ser publicados con posterioridad en otros medios o revistas, siempre que el autor indique con claridad y en la primera nota a pie de página que el trabajo se publicó por primera vez en $C E D$, con indicación del número, año, páginas y DOI (si procede). Cualquier otro uso de su contenido en cualquier medio o formato, ahora conocido o desarrollado en el futuro, requiere el permiso previo por escrito del titular de los derechos de autor.

\section{Copyright}

Copyright (for distribution, public communication, reproduction and inclusion in indexation databases and institutional repositories) of this publication (Cuadernos Europeos de Deusto, CED) belongs to the publisher University of Deusto. Access to the digital content of any Issue of Cuadernos Europeos de Deusto is free upon its publication. The content can be read, downloaded, copied, and distributed freely in any medium only for non-commercial purposes and in accordance with any applicable copyright legislation, without prior permission from the copyright holder (University of Deusto) or the author. Thus, the content of $C E D$ can be subsequently published in other media or journals, as long as the author clearly indicates in the first footnote that the work was published in $C E D$ for the first time, indicating the Issue number, year, pages, and DOI (if applicable). Any other use of its content in any medium or format, now known or developed in the future, requires prior written permission of the copyright holder. 